\title{
FLUORESCENCE DIAGNOSTICS AND PHOTODYNAMIC THERAPY IN CANCER
}

\author{
WOJCIECH DOMKA ${ }^{1}$, ŁUKASZ OŻÓG ${ }^{2}$, DOROTA BARTUSIK-AEBISHER ${ }^{3}$ \\ and DAVID AEBISHER ${ }^{2 *}$ \\ 'Department of Otolaryngology, \\ ${ }^{2}$ Department of Photomedicine and Physical Chemistry, \\ ${ }^{3}$ Department of Biochemistry and General Chemistry, \\ Medical College of The University of Rzeszow, Rzeszow, Poland
}

\begin{abstract}
Recently, fluorescence diagnostics and photodynamic therapy (PDT) is increasingly gaining in popularity for clinical use. The purpose of this review was to describe the results of using laser and molecular techniques to develop targeted cancer therapy for improved drug delivery to cancer cells with regards to tissue visualization, single-cell localization, monitoring of treatment, and drug efficacy.
\end{abstract}

Keywords: photodynamic therapy, fluorescence, photodynamic diagnosis, otolaryngology, cancer

Early detection of cancerous changes and accurate determination of their extent determine us to seek ever new diagnostic methods. Fluorescence diagnostics seem to have great potential in this regard. This technique uses the phenomenon of stimulating the fluorescence effect of cells and tissues with light. The effect in the form of lighting can be obtained by using the given agent which is a photosensitizer or by using the phenomenon of autofluorescence, i.e. the lighting of one's own cells. In each case, the reaction is based on the emission of electromagnetic radiation by the cells, caused by absorbed energy from a light source with the appropriate wavelength (1). Fluorescent techniques used to characterize the disease state of human tissue have been developed since the beginning of the 20th century (2).

An extremely important matter in the case of cancers is their proper detection and determination of their exact location. It is not uncommon to determine the range of tissues to be removed or destroyed, especially in the case of invisible latent tumors (3). There are many different techniques in radiology, such as computer tomography (CT) or magnetic resonance imaging (MRI), which help locate a tumor. However, these techniques have some limitations and, in many cases, do not provide enough information (4). However, there are other techniques that have significantly improved cancer diagnosis and evaluation. Imaging tumor lesions using fluorescent light has proved to be a very helpful diagnostic method. One of the widely used diagnostic methods using photosensitizing dyes is the photodynamic diagnosis (PDD) consisting of the detection of light emitted from cancer cells by excited chemical compounds (5). The photosensitizer that accumulates in cancer cells is photosensitive. Based on these properties, there is the possibility of more accurate diagnostics of tumors and various types of neoplastic changes. PDD allows you to see neoplastic changes that cannot be seen with conventional methods. Recently, PD Therapy (PDT) is increasingly gaining in popularity for clinical use. PDT is a treatment that uses a combination of the light-absorbing photosensitizer (PS) and dissolved singlet oxygen $\left({ }^{1} \mathrm{O}_{2}\right)$ to kill cancer. ${ }^{1} \mathrm{O}_{2}$ is generated by sensitization due to the low energy of this species, sensitizers such as porphyrins are used due to their high absorptivities.

[1] Sens + visible light (hv) $\rightarrow$ Sens*

[2] Sens* $+3 \mathrm{O}_{2} \rightarrow$ Sens $+{ }^{1} \mathrm{O}_{2}$

Fluorescence imaging is one of the most important research tools, but because of the optical properties of tissues, there is sometimes a problem

* Corresponding author: e-mail: daebisher@ur.edu.pl 
with providing light to excite molecules. Fluorescence diagnostics belongs to the non-invasive methods of imaging cancerous tissue in various locations. It finds application, among others, in oncology, ENT, dermatology, pulmonology, gynecology, and gastroenterology $(6,7)$. This method shows high sensitivity and specificity in the diagnosis of small changes, allowing to detect pathologies that were not noticed by standard procedures (6). In this method, we can separate diagnostics based on the phenomenon of autofluorescence and exogenous fluorescence enhanced with a fluorophore (8).

\section{Photosensitizers used in diagnostics}

The fluorescent properties of photosensitizers are used, among others, to identify cancerous tissue. However, it should be remembered that in addition to fluorescence, photosensitizers can also cause phototoxic effects, then PDT (9). An important role of fluorescence-based methods for medical diagnostic purposes is to show the contrast in fluorescence of diseased tissue compared to normal tissue. Such contrast is possible by using fluorochromes of endogenous tissues (autofluorescence) or by providing substances that allow specific fluorescent staining.

Tryptophan belongs to tissue fluorochromes that have the ability to autofluorescence when excited at a specific wavelength. This fluorochrome belonging to the group of amino acids and proteins is characterized by quite intense fluorescence and shows the excitation and emission maxima in the region of approximately 280 and $330 \mathrm{~nm}$ respectively (10). Another fluorochrome present in connective tissue is collagen, which is characterized by fluorescence occurring at $390 \mathrm{~nm}$ after excitation with a light length of $335 \mathrm{~nm}$ (11). Elastin is another example of a substance capable of autofluorescence with a radiation emission at $410 \mathrm{~nm}$ after excitation with $360 \mathrm{~nm}$ wavelength (12). Nicotinamide adenine dinucleotide in reduced form (NADH) is a compound found in metabolically active bacteria, and its excitation and emission maxima are in the area of approximately 330 and $440 \mathrm{~nm}$, respectively (13). The next fluorochrome is Flavin, which when excited with light at $450 \mathrm{~nm}$, shows fluorescence at 520 $\mathrm{nm}$ (14). Also, Porphyrin is characterized by autofluorescence after excitation with $405 \mathrm{~nm}$ light (15). Fluorescence diagnostics also uses exogenous drugs that are used to fluorescently stain malignant and precancerous tissues. These types of photosensitizers include tetracycline, hypericin, and the porphyrin-related substances hematoporphyrin derivative, 5-aminolevulinic acid (5-ALA) and hexyl ester hexaminolevulinate $(16,17)$.

\section{The phenomenon of autofluorescence}

Autofluorescence (AF) is a phenomenon based on the ability of some (endogenous) molecules to glow when excited by an appropriate light source (18). Molecules possessing these properties are called fluorophores and can be divided into enzogenic and endogenous (19). Ones of the more efficient endogenous fluoroforms are, among others, elastin, creatine, collagen, lipofuscin, flavin, porphyrins, aromatic amino acids, pyridoxine, and tryptophan (20-22). Some of them are located in the subepithelial layer of connective tissue, and thus the thickness of the epithelial cell layer, as well as vascularization have an impact on the obtained spectral image and the intensity of autofluorescence (22).

In the method using autofluorescence, tumor tissues are characterized by strong red fluorescence, whereas normal tissues mainly show green fluorescence (23). The red to green ratio is the basis of fluorescence endoscopy, where laser sources are used to induce fluorescence (24). Endogenous fluorescence is used to recognize cancers at an early stage, including bronchial cancer, benign bladder, and penis changes $(18,25,26)$.

\section{Diagnostic systems and fluorescence imaging in clinical practice}

Modern technologies in the field of light detection have enabled the construction of dedicated measurement systems that can be used in vivo, externally or endoscopically $(27,28)$. The main objectives of fluorescent diagnostics are detection of precancerous lesions to prevent their development, detection of cancerous tissues at an early stage of their development for rapid removal, monitoring of therapy, and possible exclusion of cancer.

One technique for performing fluorescence analysis is point spectroscopy. In this technique, a fiber optic probe is used to directly deliver light to the tissue. Then, the same probe receives the fluorescence, whose signal is delivered to the input of a spectrometer, equipped with sensitive photodetectors enabling the registration of a light signal (29). Fluorescence imaging is another technique involving the illumination of a significant area of tissue, and then recording the emitted light by a spectrally filtered camera (30). Fluorescent light sources in both techniques can be both lasers with a specific wavelength as well as light sources with a wide spectral range (xenon lamp, arc lamp). For wide spectrum light sources, it is necessary to use appropriate filters to obtain the appropriate wavelength or bandwidth. 
One of the first systems used commercially was a system in which two cameras were used to record differences in the intensity of red and green fluorescence in the two-dimensional area, induced by laser light with a wavelength of $442 \mathrm{~nm}$. This system uses a data processing algorithm to display the test area in false colors at video speeds (31). The aforementioned system showed a significant improvement in the detection of lung cancer. An additional advantage of this system was the multiple increases in detectability of dysplasia and cancer in situ. The system was intensively developed in subsequent years. Another such system based on autofluorescence was the SAFE 3000 (Pentax; HOYA Corp., Tokyo, Japan) designed by the Japanese, which enabled the use of a xenon lamp and a monochrome diode laser simultaneously. The results of subsequent studies confirmed that the system based on autofluorescence allows us to obtain better results than systems based on white light like conventional bronchoscopy $(32,33)$.

The system based on narrow-band imaging (NBI) has improved visualization of the intrabronchial microcirculation architecture. In this system, woven is illuminated by two narrow bands of light waves. A band in the range from $390 \mathrm{~nm}$ to 445 $\mathrm{nm}$ (blue band) which is absorbed by capillaries of the surface mucosa layer and a band in the range from $530 \mathrm{~nm}$ to $550 \mathrm{~nm}$ (green band) which is absorbed by hemoglobin in deeper submucosal thick blood vessels (34). Research conducted using this technique confirms its good effectiveness in differentiating normal from cancerous tissues (35-37). Another system is optical coherence tomography (OCT), in which optical imaging is based on the properties of light waves with a resolution of 1 to 20 $\mu \mathrm{m}$. Waves of these lengths allow tissue penetration up to $3 \mathrm{~mm}$. This type of system allows high-resolution cross-sectional images of central airways to be obtained (38). For non-invasive optical imaging techniques that enable real-time histological imaging is confocal laser endomicroscopy (CLE). This system uses a $488 \mathrm{~nm}$ wavelength laser from which a light beam is directed into the alveolar space. This system uses information obtained thanks to the autofluorescence properties, which has allowed, inter alia, to differentiate and characterize lung cancer, which has been confirmed by numerous studies (3941). Research conducted by Fuchs et al. using the CLE-based system showed that the use of a contrast agent in the form of fluorescein and acriflavine hydrochloride improves the detection of epithelial bronchial cells in patients with suspected lung cancer $(42,43)$.
Fluorescence spectroscopy and lifetime techniques have been found to be helpful in diagnosing cancer $(44,45)$. The molecular contrast compromised by endogenous fluorophores present in tissues is the basis of this technique. Fluorescence emitted by fluorophores recorded as an emission spectrum for comparison between differences in separate tissues. This is possible due to the intensity of the peaks and the shape of the spectral lines, which are used in comparative analysis. Fluorescence spectroscopy is divided into steady-state techniques, i.e. spectral or intensity measurements and timeresolved (time-domain and frequency-domain) techniques. Of these techniques, steady-state fluorescence spectroscopy is used to obtain biological and biochemical information related to tissue molecular composition (46). Gillenwater et al. in their research they used fluorescence spectroscopy to detect in vivo oral cancer (44). By scanning the tissue with a small fiber-optic probe, subtle changes in the tissue can be detected by analyzing the fluorescence spectrum it emits. Measurements with time resolution take advantage of the disappearance of fluorescence intensity, thus enabling additional information on fluorescence dynamics that characterizes the studied structures. Biomolecules with overlapping fluorescence emission spectra but different fluorescence decay times can be discriminated by this technique. Measurements using this technique are resistant to changes in fluorescence excitation geometry (e.g. presence of hemoglobin, photobleaching, changes in fluorophore concentration, excitation intensity), making them more suitable for clinical trials. By resolving the emission during fluorescence emission at many wavelengths in the entire emission spectrum, the full spectrum of fluorescence emission (steady-state) can be obtained (47). Measurement of fluorescence lifetime in the time domain is based on the time distribution of photon survival times after each excitation pulse (48). The measurement method based on measuring fluorescence lifetime in the frequency domain is based on faozym shift or amplitude modulation depending on the frequency of the modulated excitation that reaches the sample. One of the most used time-domain fluorescence lifetime techniques is the time-correlated single-photon counting (TCSPC). In this technique, the time between the light pulse and the photon reaching the detector is measured. In the case of biological molecules, the measured times are on the order of nanoseconds. Most of the measurements are performed in cell cultures, and ex-vivo normal and abnormal tissues, therefore, clinical measurements of fluorescence lifetime in vivo using portable sys- 
tems are important. Gallety et al. 2008 they used fluorescence lifetime imaging (FLIM) and were able to distinguish areas of basal cell carcinomas (BCC) from surrounding skin in an ex vivo study (49]) Patalay et al. using this technique, showed significant differences between benign and nodular BCC (50).

There are several obstacles to the implementation of the technologies described above, including equipment availability, costs, training, and practical technology limitations. There is also concern not a small number of false-positive findings of incorrect changes, which, however, is unfortunately not only in the case of PDD $(51,52)$. Fluorescence diagnostic systems are still being developed to increase the specificity of this method. Digital image processing on fluorescent images and overlaying on images obtained using white light can further improve the diagnostic accuracy of this method (53).
Photodynamic therapy - scientific reports over the years

All literature items on the chart (Figure 1-6) have been searched in PubMed with the combination of keywords "breast cancer photodynamic therapy", "colon cancer photodynamic therapy", "oral cavity photodynamic therapy", "laryngeal photodynamic therapy", "lung photodynamic therapy" and "prostate photodynamic therapy" to collect articles that referred to PDT.

Photodynamic diagnostic and therapy in Europe, North America, and Asia - clinical trials in recent years

\section{PDD and PDT in Poland - clinical trials}

In 2006, a study in which they applied azone (1-dodecyl-azepan-2-one) before the application of 5-ALA in patients with plantar warts: mosaic warts (MW) and Myrmecia (MY) was conducted. The use

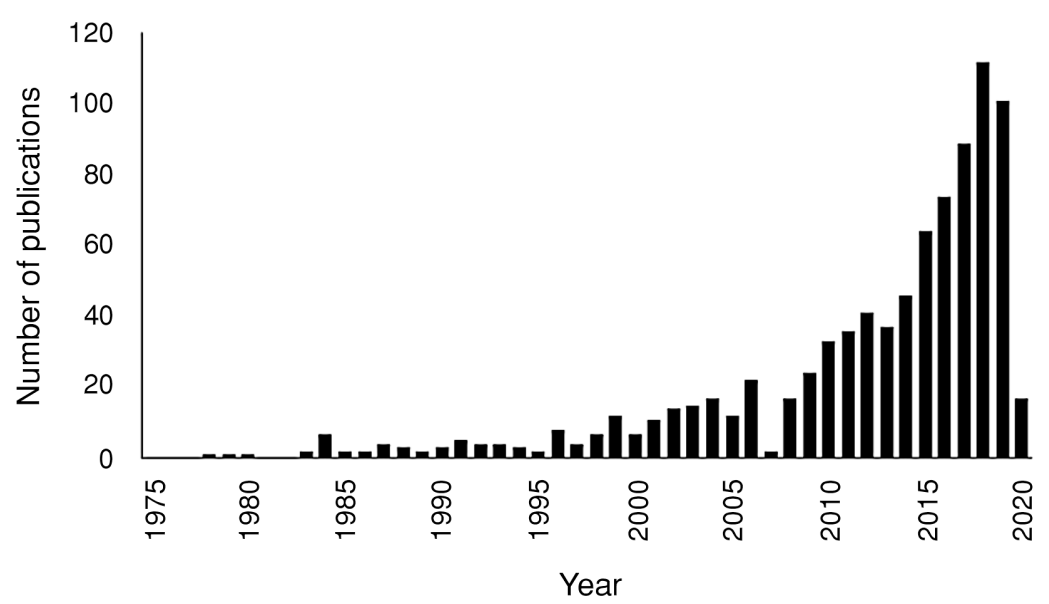

Figure 1. The number of scientific publications in the years 1975-2020 based on the search for "breast cancer photodynamic therapy" in the PubMed database.

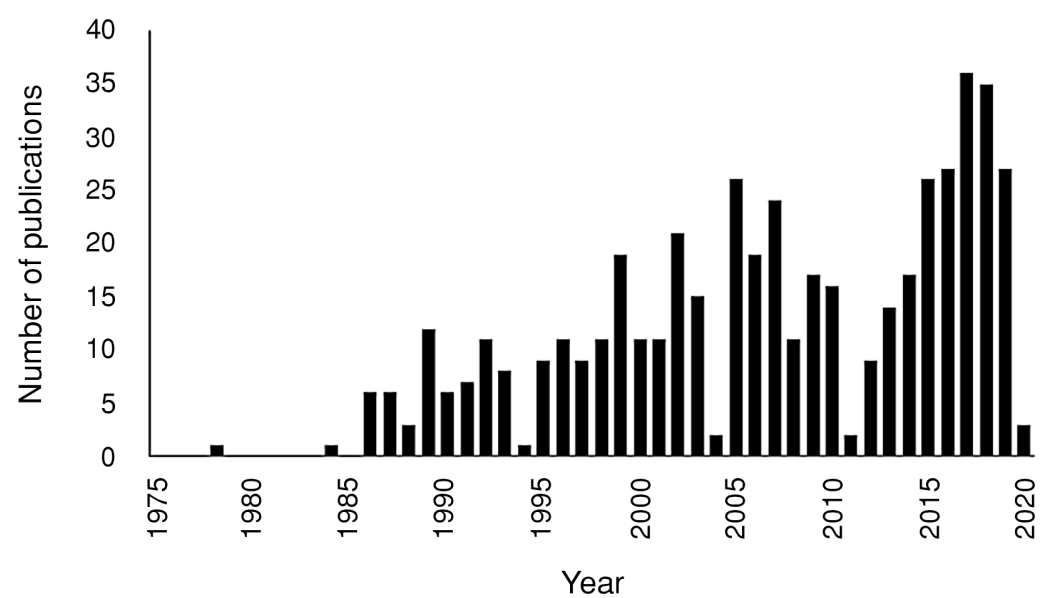

Figure 2. The number of scientific publications in the years $1975-2020$ based on the search for "colon cancer photodynamic therapy" in the PubMed database. 


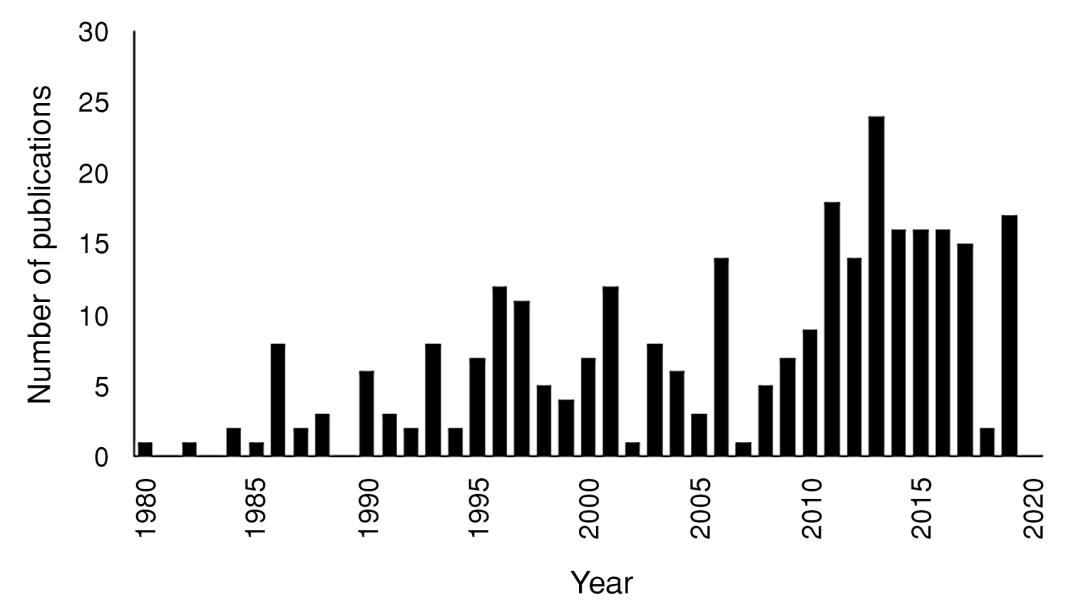

Figure 3. The number of scientific publications in the years 1980-2020 based on the search for "oral cavity photodynamic therapy" in the PubMed database.

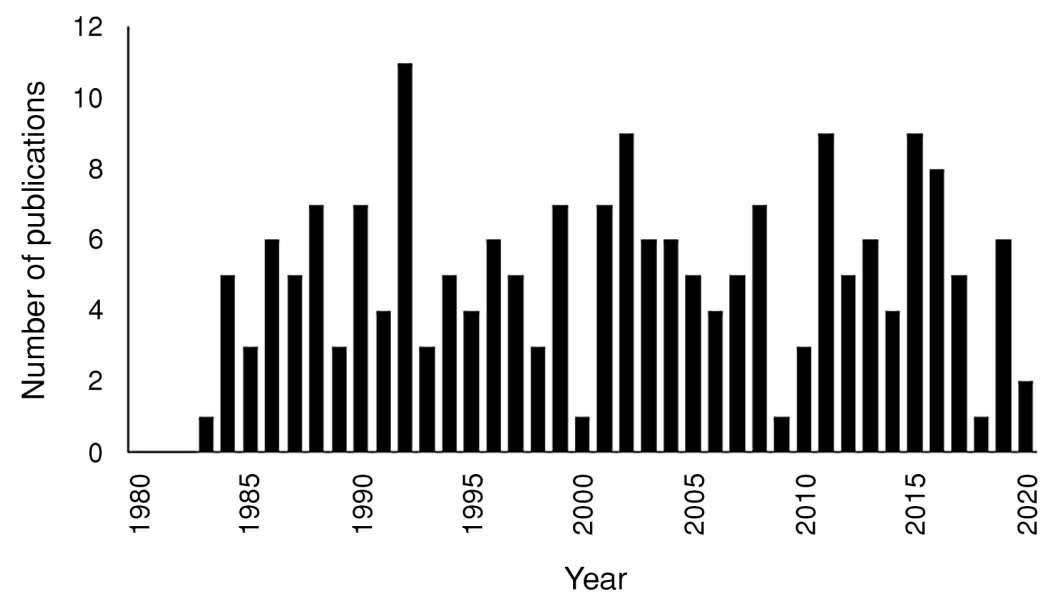

Figure 4. The number of scientific publications in the years 1980-2020 based on the search for "laryngeal photodynamic therapy" in the PubMed database.

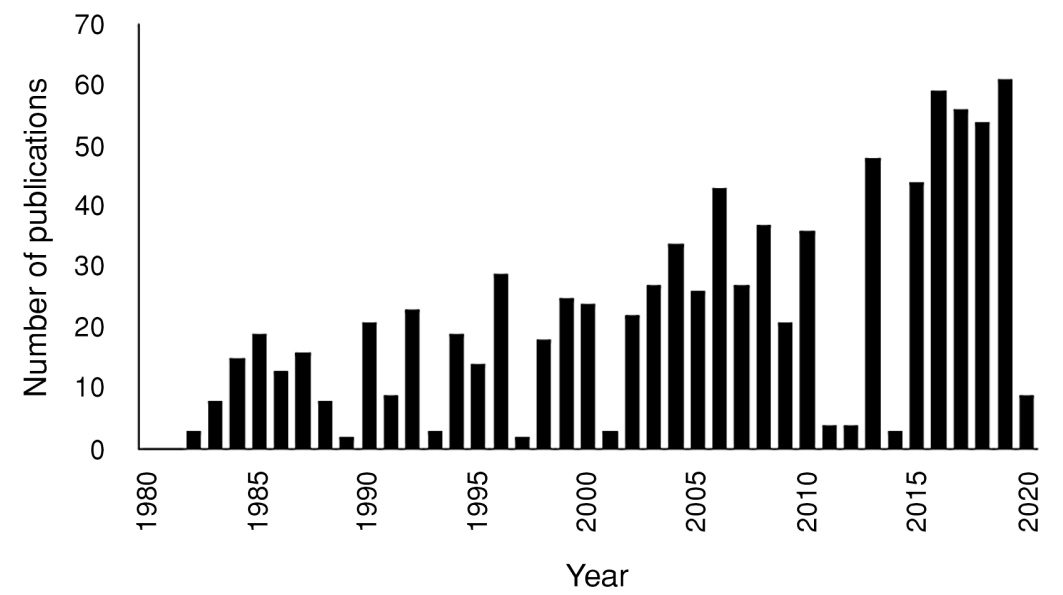

Figure 5. The number of scientific publications in the years 1980-2020 based on the search for "lung photodynamic therapy" in the PubMed database. 


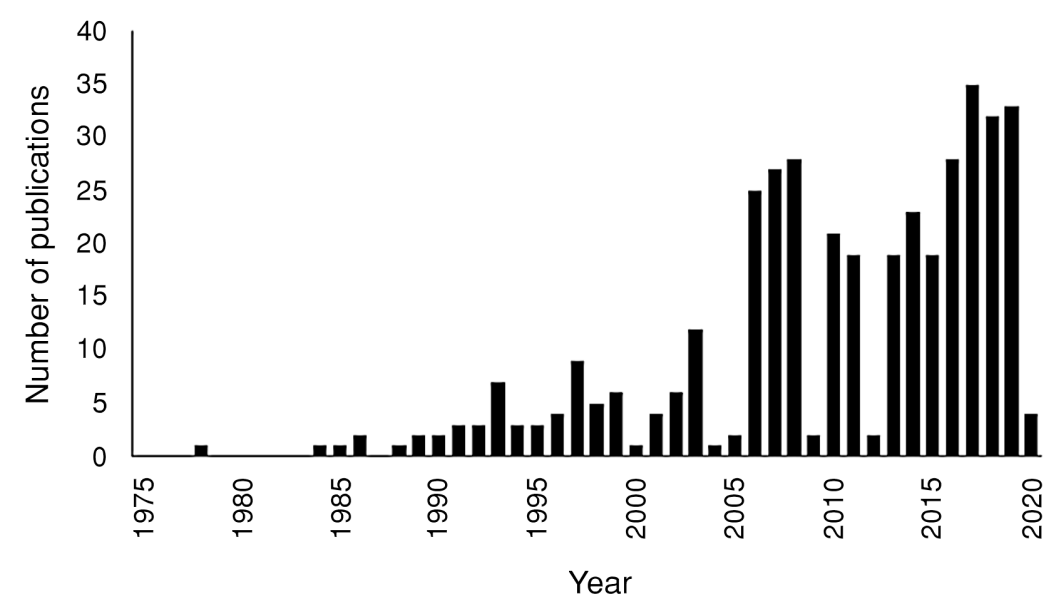

Figure 6. The number of scientific publications in the years 1975-2020 based on the search for "prostate photodynamic therapy" in the PubMed database.

of azone was aimed at increasing the penetration of 5-ALA through the affected skin. The results of their research showed that pre-treatment with azone significantly increases the penetration of 5-ALA in tissues, and thus increases the effectiveness of PDT (54). Olejek et al. in 2009, they conducted research that aimed to check the effectiveness of photodynamic therapy in the treatment of lichen sclerosus. In the PDT study using 5-aminolevulinic acid (ALA) as a photosensitizer, 28 women participated. Before PDT, all patients suffered from itching, and after almost $90 \%$ relief was noted, and more than $35 \%$ of patients did not have lichen sclerosus after the end of therapy, which was confirmed by histological studies (55). In 2012, research was carried to assess the effectiveness of local photodynamic therapy supplemented by the local application of Aldara in basal cell carcinoma. 34 patients were treated with PDT. The use of Levulan based photodynamic therapy with imiquimod resulted in a complete cure of $75 \%$ of patients, and 6 lesions were significantly reduced. The presented results showed the effectiveness and validity of the proposed PDT modification (56). A study in 2012 aimed to compare cryotherapy and photodynamic therapy in the treatment of oral leukoplakia was conducted. One group of 48 patients was treated with photodynamic therapy using ä-aminolevulinic acid (ALA) as a photosensitizer, the other group of 37 patients was treated with cryotherapy. The results of these studies have shown that both therapies show similar efficacy and both methods of treatment can serve as alternatives to traditional surgical treatment of oral leukoplakia. In addition, researchers suggested that PDT is more convenient for patients, less painful and more aes- thetic (57). Maździarz et al. in 2013, they conducted studies aimed at assessing the effectiveness of the PDD photodynamic method in detecting vulvar lesions using two ALA concentrations, as well as assessing the effectiveness of this method compared to the effectiveness of vulvoscopy compared to the result of a histological examination. To obtain fluorescence, energy in the form of light with a wavelength of $405 \mathrm{~nm}$ was transferred to the vulva tissue. The obtained results showed a high correlation between the accuracy of the PDD method in the study of vulvar lesions and the accuracy of histological examination, especially in the case of precancerous lesions and vulvar cancer. The observed fluorescence obtained during the PDD study provided important information on the spread and diversity of vulvar lesions (58). In 2014, the team from Białystok also conducted research on PDT in the treatment of oral leukoplakia. The aim of these studies was to evaluate the clinical effectiveness of photodynamic therapy using the Photolon ${ }^{\circledR}$ photosensitizer containing $20 \%$ e6 chlorine and $10 \%$ dimethyl sulfoxide. The results showed comparable efficacy of PTD in women and men regardless of age. After treatment, a significant reduction in the size of leukoplakia lesions was observed, and no adverse effects were noted at the site of therapy (59). In 2017, researchers from Wrocław presented the results of research on the treatment of vulvar sclera lichen using photodynamic therapy. The study included a group of 11 patients with lichen sclerosus (LS). The therapy uses 5-aminolevulinic acid (5ALA) and green light instead of red to eliminate local pain during radiation. A reduction in pruritus and a significant improvement in local conditions 
were observed after PDT treatment. In addition, none of the patients complained of pain during the radiation (60). Two years later Osiecka et al. conducted a comparative study that aimed to compare the efficacy and tolerability of local aminolaevulinic acid therapy - photodynamic treatment of actinic keratosis (AK) on the head using red and green light. The results showed that PDT with green light for AK has similar efficiency as when using red light. An additional advantage of using green light was less pain felt by patients (61).

Below is a graph (Figure 7) showing the number of scientific publications on photodynamic therapy in Poland based on a search of the PubMed database (not including review articles).

\section{PDD and PDT in Germany}

In 1989, Jocham et al. conducted a study in which they used photodynamic therapy in 15 patients with TIS bladder carcinoma. Other treatments that were used in these patients were not fully effective because there was a recurrence of surface bladder tumors after treatment. The use of PDT brought positive results. Nine patients had no tumor recurrence following PDT treatment. In other cases, re-PDT was required to achieve complete recovery (62). Kriegmair et al. also conducted studies in which they used photodynamic therapy as an alternative treatment method for patients with bladder cancer. Using a $630 \mathrm{~nm}$ wavelength laser and a synthetic porphyrin mixture that was injected intravenously, the bladder was irradiated in 21 patients. High efficiency of treatment was achieved in this way, and the use of the PDT method also allowed to protect healthy bladder tissues (63). In 1996,
Szeimes et al. performed PDT using 5-aminolevulinic acid in the treatment of actinic keratosis. 10 patients with 36 lesions on the arms, shoulders and head were treated. The results of the study showed good method effectiveness and tolerance to local ALA-PDT (64). Clinical trials with the use of PDT in the treatment of head and neck cancer were conducted in 1988 - 1994 in Munich. 83 patients with facial tumors, oropharynx and larynx were treated with PDT. Tumors and surrounding tissues were illuminated with a $630 \mathrm{~nm}$ wavelength laser, and Photosan-3 was used as a photosensitizer. The results of these studies have shown that PDT works as a method of treatment in the case of superficial cancer, in addition in most cases in the ENT area, general or local anesthesia is not required (65). Messmann et al. in 1997 they conducted a study in which they showed that modified laser treatment can enhance the effect of PDT in patients with esophageal cancer after hematoporphyrin sensitization (66). In 1998, the team led by Waidelich carried out PDT after oral administration of 5-aminolevulinic acid in 4 patients with extensive superficial papillary tumors of the upper urinary tract. The results of the study showed that PDT is a minimally invasive approach to conservative treatment of the organ in multifocal superficial transient upper urinary tract cancer (67). Schmidt-Erfurth et al. described the studies in which PDT was used for subfoveal choroidal neovascularization (CNV). Benzoporphyrin derivative monoacid ring A (BPD) as a photosensitizer was used in these studies. 61 patients received a single BPD-PDT cycle. Test results showed clinical damage to retinal structures in the treatment area and retinal perfection.

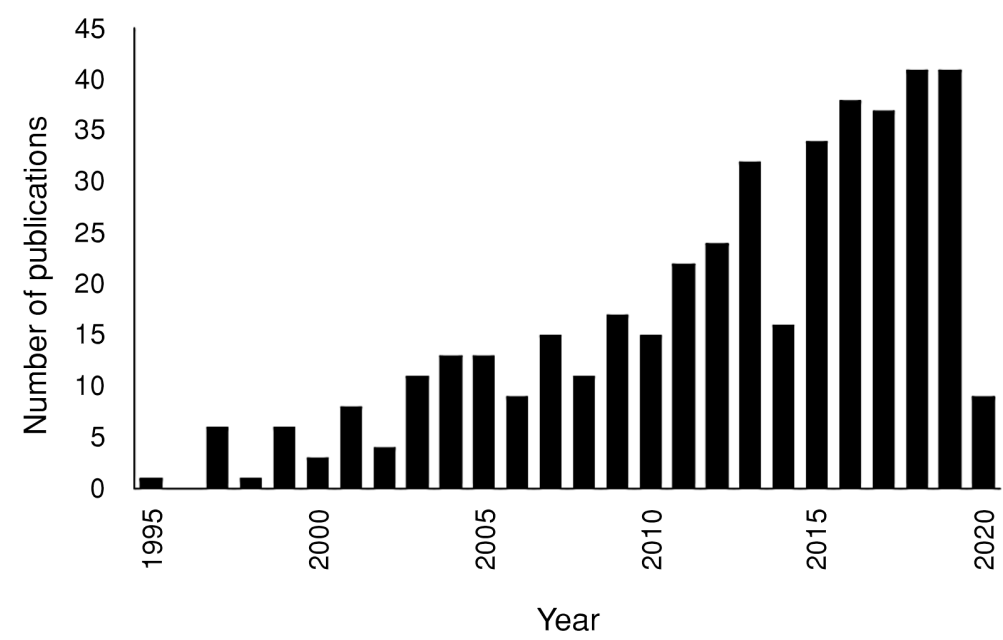

Figure 7. Number of scientific publications on research into photodynamic therapy in Poland (excluding review articles). The chart was based on searches in the PubMed database. 
Researchers have confirmed that PDT allows for the temporary absence of CNV leakage while maintaining visual acuity (68). In 1999, studies were conducted using 5-aminolevulinic acid (5-ALA) as a photosensitizer in PDT in women with endothelial cervical cancer (CIN). Studies have shown that PDT causes minimal side effects. The analysis of all results showed that 5-ALA-PDT did not show high efficacy in the treatment of CIN (69). Berr et al. in 2000 they conducted a study to see if local photodynamic therapy for inoperable bile duct cancer could improve survival. 23 patients participated in the study. Studies have shown that PDT can prevent tumor occlusion of hilar bile ducts and improved palliation and extended survival (70). Löning et al. in 2004 conducted clinical trials to assess the detection of fluorescence in vivo metastasis of ovarian cancer in the second laparoscopic procedure following the intraperitoneal use of 5-aminolevulinic acid (ALA). The use of ALA resulted in the endogenous production of the fluorescent photosensitizer, protoporphyrin IX (PP IX). By means of blue light illumination, intraperitoneally localized red fluorescent lesions, which were suspected of metastases, were biopsied. Research results have shown that direct visualization of fluorescence in vivo after the use of ALA can improve the early detection of intraperitoneal micrometastasis of ovarian cancer (71). In 2007, Stepp et al. described the studies in which resection under fluorescence control and photodynamic treatment in malignant glioma were performed (72). In 2007, Berking et al. published research results in which they evaluated the efficacy of photodynamic therapy in actinic cheilitis of the lower lip. 13 patients underwent PDT treatment. Studies have shown that PDT is an effective and non-invasive method of treating the type of diseases (73). In 2008, Soergel et al. checked the feasibility and response to PDT treatment with hexaminolevulinate (HAL) in cervical intraepithelial neoplasia (CIN) and human papillomavirus (HPV) infection. The results of these studies have shown that HALPDT is a repetitive and non-invasive procedure that is characterized by minimal side effects (74). Adam et al. in 2009 they conducted research that aimed to find a fluorescent marker for photodynamic diagnosis (PDD), thanks to which tumor margins will be visible during surgery. Studies conducted on a group of 39 patients with prostate cancer have shown that PDD using protoporphyrin IX induced with 5-aminolevulinic acid (P-PIX) can be a feasible and effective method in increasing surgical radicality (75). In 2013, Johansson et al. conducted a study of protoporphyrin IX fluorescence and photobleaching during interstitial photodynamic therapy of malignant gliomas for early treatment prognosis. Realtime monitoring of PpIX fluorescence intensity and photo-bleaching proved feasible and safe. In addition, researchers reported that this method can be used for early forecast treatment (76). Hillemanns et al. in 2017, they conducted a study to check the effectiveness of PDD using 5-aminolevulinic acid (ALA) in detecting metastases of ovarian cancer to the peritoneum. 26 patients were examined. The results of these studies have shown that PDD with ALA enables safe and specific detection of peri-

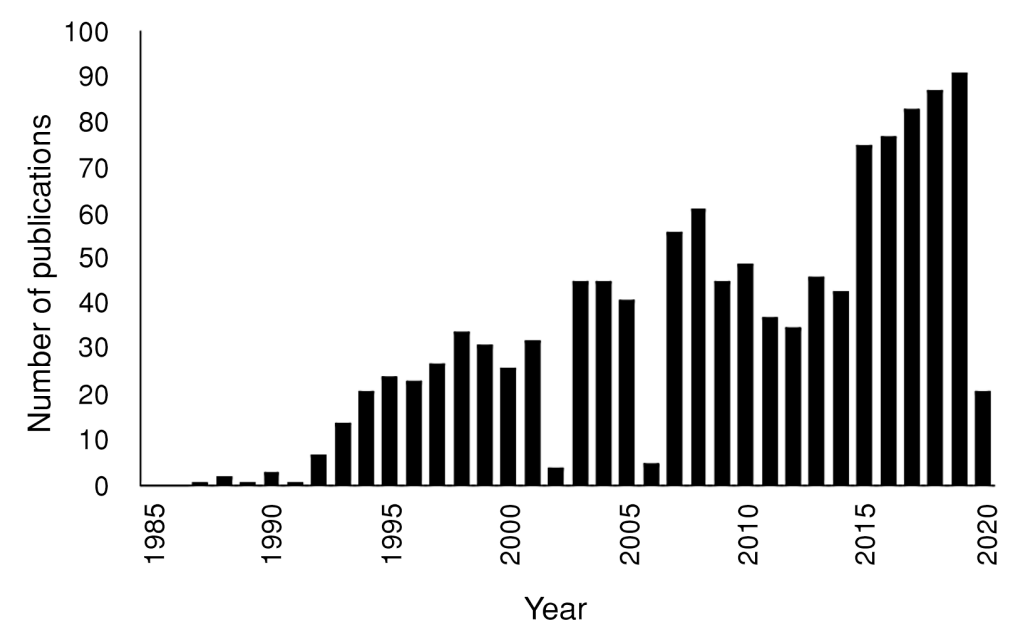

Figure 8. Number of scientific publications on research into photodynamic therapy in Germany (excluding review articles). The chart was based on searches in the PubMed database. 


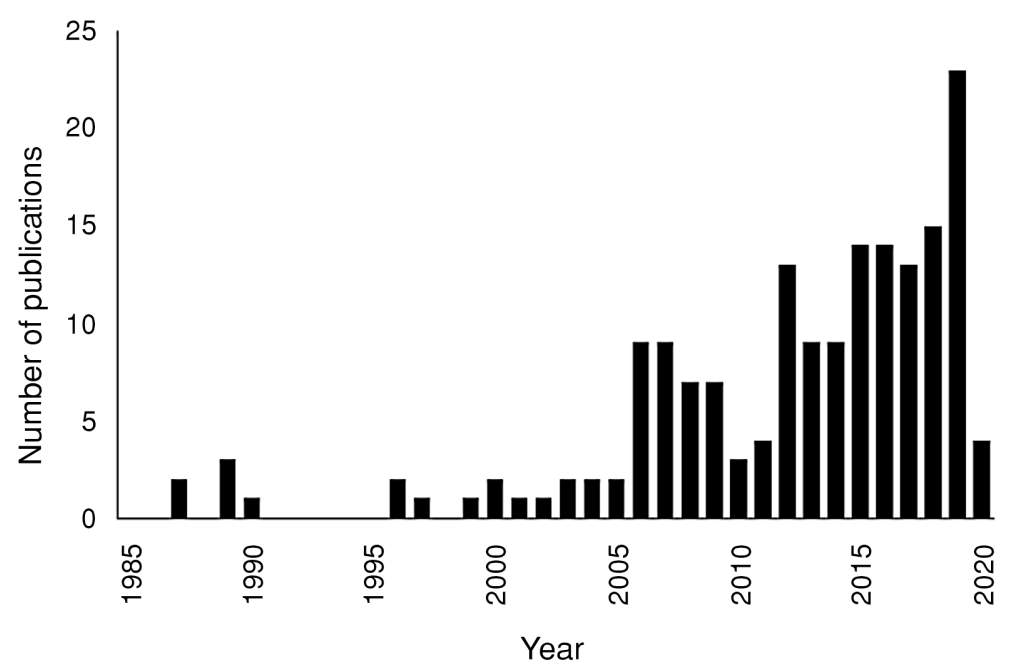

Figure 9. Number of scientific publications on research into photodynamic therapy in Denmark (excluding review articles). The chart was based on searches in the PubMed database.

toneal metastases fluorescence (77). In 2018, studies were performed in which patients with actinic keratoses on the head received PDT treatment using ALA. The novelty in this study was to match the light wavelength to the absorption peaks of Protoporphyrin IX (PPIX). The results showed that the proper selection of light wavelengths increases the safety and effectiveness of PDT in the treatment of patients with actinic keratoses (78). Figure 8 presents the increase in the number of papers describing PDT clinical trials research in Germany (Figure 8).

\section{PDD and PDT in Denmark - clinical trials (Figure} 9)

In 1987, Hugh-Jones and Gardner applied laser photodynamic therapy to patients with inoperable bronchogenic squamous carcinoma. Either haematoporphyrin derivative or dihaematoporphyrin ether was found in PDT therapy. All tumors responded to PDT treatment (79). Stender and Wulf conducted PDT in three patients with cheilitis. 5aminolevulinic acid (ALA) was used in therapy, and incoherent visible light was used for irradiation. The therapy proved effective and no sign of fertilizer was observed 6 and 12 months after treatment (80). In 1999, Stender et al. conducted a study to determine whether PDT with topical application of 5aminolaevulinic acid (ALA) is an effective treatment for resistant warts in the hands and feet. 30 patients took part in the study. The results of the research have shown the high effectiveness of this method. At 12 months after treatment, no relapses were observed (81). In 2005, Nybaek and Jemec conducted a study in which they used PDT to treat rosacea. PDT was performed successfully in 4 patients. Their results have shown that PDT may play a role in the treatment of selected cases of rosacea (82). In 2006, Wiegell and Wulf conducted a study to compare the therapeutic effects of aminolevulinic acid-PDT (ALA-PDT) and methyl aminolevulinate-PDT (MAL-PDT) in the treatment of acne vulgaris. The PDT method proved to be effective in the treatment of inflammatory acne lesions in both photosensitizers. The researchers reported that ALA-PDT caused longer and more severe side effects after therapy (83). In 2007, Christiansen et al. conducted research on the photodynamic effect of 5-aminolaevulinic acid (ALA) in the process of photorejuvenation of the skin. Patterns of skin fluorescence distribution were studied after the topical application of low ALA concentrations. Studies have shown that low ALA levels allow good results to be obtained while reducing the risk of phototoxicity after treatment (84). Wiegell et al. in 2009 described studies that compared response rates and side effects after PDT using $16 \%$ and $8 \%$ methyl aminolevulinate (MAL) with home exposure to daylight in the treatment of actinic keratosis (AK). The results of these studies showed that the use of MAL-PDT was effective and well-tolerated AK treatment (85). In 2011, Hermann et al. used fluorescence diagnostics with hexaminolevulinate (HAL) in patients diagnosed with a bladder tumor. A total of 233 patients participated in the studies. 


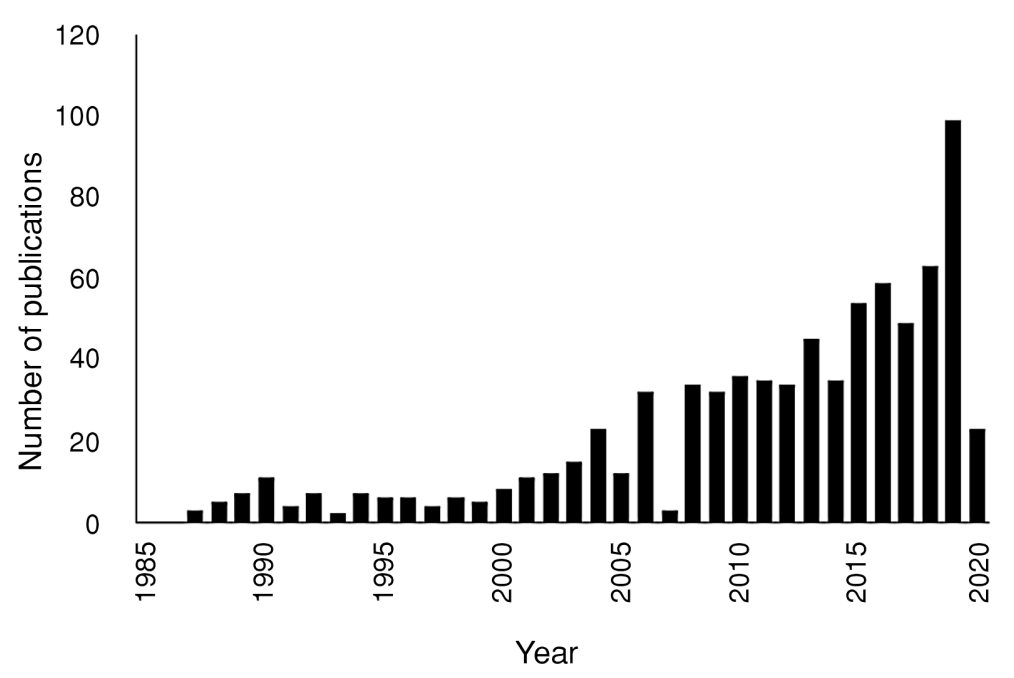

Rysunek 10. Number of scientific publications on research into photodynamic therapy in Italy (excluding review articles). The chart was based on searches in the PubMed database.

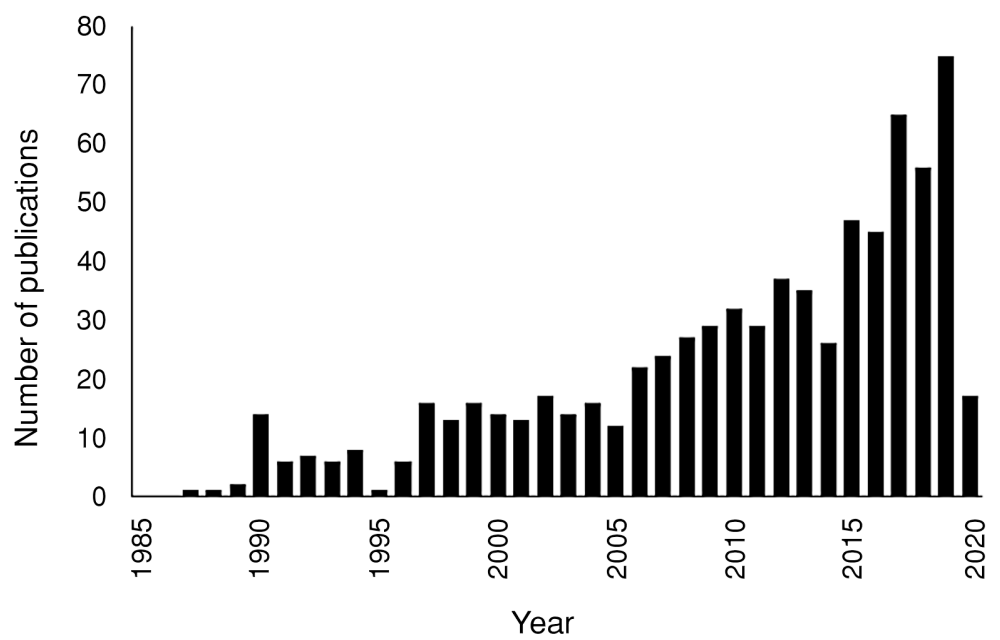

Figure 11. Number of scientific publications on research into photodynamic therapy in France (excluding review articles). The chart was based on searches in the PubMed database.

Fluorescence diagnostics using HAL improved the detection of bladder tumors and allowed a reduction in the rate of relapses (86). Haak et al. in 2015 described studies aimed at assessing the efficacy and safety of PDT involving ablative fractional lasers (AFXL) and methyl aminolevulinate (MAL) compared to conventional PDT for nodular basal cell carcinomas (nBCC). The results showed similar efficacy in both treatments. AFXL-PDT was characterized by a positive short-term cure rate (87).
PDD and PDT in Italy - clinical trials (Figure 10)

In 1988, Perria described research using a device that allows percutaneous treatment of robotic malignant brain tumors. Rickham's Holter reservoir enabled the introduction of a photosensitizer into the tumor cyst, and light by using optical fiber to induce a photodynamic process (88). Corti et al. described studies in which 26 patients with gynecological cancers were treated with hematoporphyrin 
(HP) treatment (89). In 1999, Patelli et al. used PDT to treat early-stage bronchial cancer. 26 patients took part in the study. The results of their research confirmed the effectiveness of this method in the treatment of surface lung cancer (90). In 2000, Corti et al. published a study in which they examined the effect of PDT on inoperable early-stage esophageal cancer. 62 patients were treated with hematoporphyrin. The research results have shown that PDT is an effective regimen for early esophageal cancer and brings many benefits in this type of cases (91). In 2003, Porrini et al. performed PDT in patients with circumscribed choroidal hemangioma $(\mathrm{CCH})$. PDT treatment with verteporfin (Visudyne) involved 10 patients. Therapy has proved to be an effective method of treating CCH (92). Fossarello et al. also used verteporfin to treat PDT patients with corneal neovascularization $(\mathrm{CNV})$. The results showed that the therapy has positive effects, however, multiple sessions are required (93). Rossi et al. in 2004 they conducted a study in which squamous cell carcinoma was treated using PDT. The photosensitizer used during the study was 5-aminolevulic acid (ALA). The results showed that treatment with the PDT method allows achieving good results in patients who cannot undergo surgery (94). In 2007, Surrenti et al. conducted a study to assess the effectiveness of PDT using methyl aminolevulinate (MAL-PDT) in the treatment of superficial and nodular basal cell carcinoma (BCC). 69 patients were treated. The results were positive, BCC treatment with the MALPDT method showed high efficiency (95). Bombeccari et al. in 2013 conducted a study in which they used PDT to treat per-implant inflammation. The use of PDT therapy showed similar efficacy compared to surgical treatment. In addition, patients treated with the PDT method had a lower pro-inflammatory index after 24 weeks of follow-up (96). In 2019, Serini et al. conducted a study to evaluate the efficacy and tolerability of 5-aminolevulinic acid 5\% thermosetting gel PDT in the treatment of acne vulgaris. 35 patients were examined. The results of the study confirmed the effectiveness of this method despite the reduction of ALA concentration (97).

PDD and PDT in France - clinical trials (Figure 11)

In 1990, Freche and De Corbiere conducted a study in which they used PDT to treat vocal cord cancer. The study involved 32 patients who were injected with a hematoporphyrin derivative (HpD). Researchers reported 25 positive responses to PDT (98). In 1994, Foultier et al. conducted research aimed at using PDT using a hematoporphyrin (HpD) derivative in the treatment of gastrointestinal cancer. The study involved 32 patients. Research results have shown that PDT acts directly on cancer cells in humans, not just tumor blood vessels (99). In 2002, Quaranta et al. conducted a study in which they used the PDT method based on verteporfin (Visudyne) in patients with exudative idiopathic polypoidal choroidal vasculopathy. The study results showed the effectiveness of verteporfin and no relapses during the observation period (100). Erienne et al. in 2004, they conducted studies aimed at assessing the

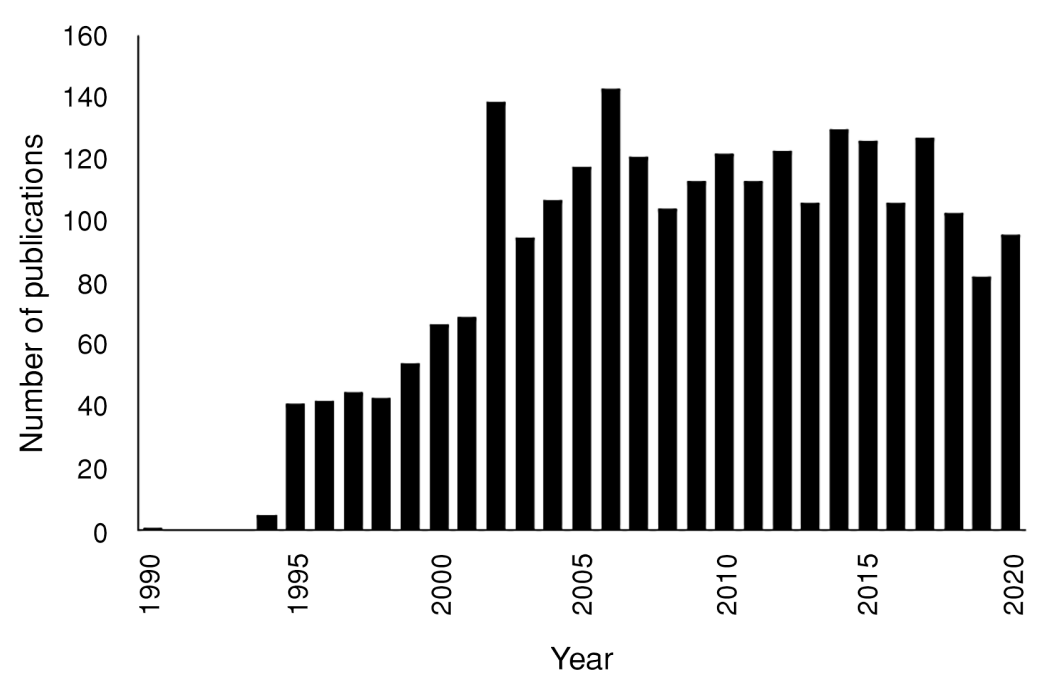

Figure 12. Number of scientific publications on research into photodynamic therapy in the USA (excluding review articles). The chart was based on searches in the PubMed database. 
efficacy and tolerance of PDT using green light and photosensitizers temoporfin or m-tetrahydroxyphenyl chlorin in patients with Barrett's esophagus and early-stage neoplastic lesions. 12 patients were treated. The results of the study showed $100 \%$ effectiveness of the method, the use of m-tetrahydroxyphenyl chlorin and green light enabled the elimination of early malignant lesions in the esophagus (101). In 2005, Maunoury et al. performed PDT treatment with Photofrin on a group of 24 patients with early esophageal cancer. The research results confirmed the effectiveness of this method of treatment in this type of cancer (102). Trachenberg et al. in 2008 performed targeted PDT on blood vessels for recurrent prostate cancer. Patients received a dose of TOOKAD photosensitizer (WST 09), and then the prostate area was illuminated using fiber optics under ultrasound control. The results of the study confirmed the clinical potential of PDT in the treatment of prostate cancer recurrence (103). In 2008, Taks-Seeguin et al. applied topical PDT treatment with methyl aminolevulinate (MAL-PDT) in patients with superficial basal cell carcinoma. The study involved 60 patients. The results of the study confirmed the effectiveness of MAL-PDT in the treatment of this type of cancer, 100 of 114 lesions covered by the treatment showed a complete response to the use of PDT (104). In 2013, Azzouzi et al. used PDT to treat patients with prostate cancer. 85 patients were treated with the PDT method. The results showed the effectiveness of the method and low side effects (105). PDT treatment in patients with a low risk of prostate cancer was used by Lebdai et al. in 2017. The study involved 82 patients who were treated with targeted vascular-targeted photodynamic therapy. The photosensitizer used in this study was Padeliporfin. The results were positive and radical therapy was avoided in more than $75 \%$ of cases (106).

PDD and PDT in USA - clinical trials (Figure 12) In 1990, McCaughan reported the positive effects of PDT on patients with skin and esophageal cancer. PDT treatment was performed in 27 patients with malignant skin and subcutaneous lesions and 40 patients with esophageal tumors. Treatment was carried out using surface or interstitial radiation. The goal of the therapy was to improve the patient's ability to swallow. The applied PDT reduced the size of tumors by an average of $1 \mathrm{~cm}$, while the diameter of the hole increased from 6 to $9 \mathrm{~mm}$. In addition, PDT treatment resulted in improved food intake in treated patients and the transition from a liquid to a soft diet (107). Researchers from Roswell Park Cancer
Institute in 1995 conducted a study in which they used PDT as an adjunct to radical surgery for the treatment of locally recurrent rectal cancer. The study involved 22 patients who were injected with Photofrin prior to surgery. During the study, one serious morbidity was reported due to PDT. Researchers suggested that intraoperative PDT PDT can be safely administered to patients undergoing resection of recurrent rectal cancer. However, they emphasized that the use of PDT in the current state of technology seems inappropriate to combat the disease (108). In the same year, Takita and Dougherty explored the possibilities of using PDT in 31 patients with malignant pleural mesothelioma disease. Photofrin was injected at a dose of $2 \mathrm{mg} / \mathrm{kg}$ 48 hours before surgery. After tumor resection, the area was illuminated with a $630 \mathrm{~nm}$ wavelength laser. The use of intravascular PDT allowed achieving a median patient survival of 12 months (109). McCaughan et al. in 1996 they described PDT for esophageal malignancy. From 1982 to 1994, 77 patients with esophageal carcinoma were included in the PDT treatment. All patients were ineligible for surgical intervention, ionizing radiation therapy, or chemotherapy. The results of these many years of research showed that PDT esophageal cancer caused minimal complications and did not cause deaths related to the procedure and PDT can be considered as an alternative treatment in patients with Barrett's esophagus (110). In 1996, Nseyo published the results of 13 studies on PDT in the treatment of bladder cancer. A total of 58 patients underwent PDT treatment with PS Photofrin and $630 \mathrm{~nm}$ laser light. Research results have shown that PDT is an effective therapy for superficial bladder cancer (111). Weber et al. in 1997 they conducted research on a non-invasive fluorescence technique for detecting gastrointestinal cancer and PDT using 5-aminolevulinic acid (ALA). The aim of the study was to indicate the moment when the tissue levels of protoporphyrin IX (PP) are at a maximum, which allows for maximum effectiveness of PDT. Research results suggested that the tumor surface fluorescence intensity correlates with the tumor PP concentration (112). Taber et al. in 1998 they conducted a study in which PDT was used to palliation of chest wall recurrence in patients with breast cancer. Seven patients with breast cancer were treated using PDT. Research results have shown that PDT is an effective treatment for chest wall recurrence in patients with breast cancer in whom other treatments have failed (113). Overholt et al. in 1999 they performed PDT treatment in patients with esophagus and Barrett's dysplasia or superficial esophageal 
cancer. PDT was used in one hundred patients, including 13 with superficial tumors. All patients had a conversion of approximately $80 \%$ of the treated Barrett mucosa to normal squamous epithelium. The test results confirmed the effectiveness of PDT (114). Krishnamurthy et al. in 2000 they conducted research to optimize interstitial PDT in the treatment of brain malignancies. In this study, 18 patients participated, including 12 patients with glioblastomas, 5 patients with anaplastic astrocytoma, and 1 patient with malignant ependymoma. The results showed that increasing the light dose did not significantly improve the efficacy of PDT. Four patients had longer survival after using PDT (115). Madreperla in 2001 described a study in which patients with choroidal hemangioma were treated with PDT using Veteroprfin. PDT treatment was used in 3 patients. The results showed that all patients had complete subsidence of the retinal fluid and improved visual acuity as a result of PDT treatment (116). In 2002 Spaide et al. used PDT to treat polypoidal choroidal vasculopathy $(\mathrm{PCV}) .16$ patients participated in the study. The results of the research showed that the treatment with PDT did not cause any complications in treated patients. As a result of treatment, visual acuity was positively correlated with baseline and negatively with age (117). Barbazetto et al. in 2003 investigated the effect of PDT using verteporfin on choroidal melanoma. Four patients with choroidal melanoma were treated with PDT. The use of PDT saved two eyes that could not be healed by other therapies. One of the tumors decreased and the other showed no increase due to PDT (118). Friedberg et al. in 2004 conducted studies to assess the efficacy and impact on survival of PDT therapy in patients with non-small-cell lung cancer (NSCLC) with pleural spread is incurable. 22 patients were treated with PDT. The median survival of PDT was approximately 22 months. These encouraging research results have shown that further research on PDT in this type of disease is justified (119). In 2005 Bakri and Beer described the results of clinical studies of four eyes with macular edema due to radiation retinopathy treated with PDT using verteporfin. As a result of PDT treatment, four eyes had a clear reduction in hard exudate, three of four eyes had improvement (120). Richey and Hopson in 2006 evaluated the efficacy and safety of PDT with topical 5-aminolevulinic acid (ALA) in the treatment of perioral dermatitis. The study was conducted on a group of 21 patients. The average level of patient satisfaction after PDT treatment was 4.4 on a scale of 1 to 5. Studies have shown that ALA-PDT can be an alternative to antibiotic treatment in perioral der- matitis (121). Tierney et al. in 2008 they conducted a study comparing the effectiveness of PDT with other methods (cryotherapy, surgery) in the treatment of actinic keratoses (AKs). 39 patients took part in the study. Study results have shown that PDT has equivalent or improved recovery times, cosmetic results, patient satisfaction, and preferences as a treatment for $\mathrm{AK}$ in patients compared to other options (122). Housel et al. in 2010 they described research on noninvasive extramammary Paget's disease (EMPD) treated with PDT. PDT clinical results were analyzed using topical aminolevulinic acid (ALA) or intravenous porfimer sodium as photosensitizing agents and argon laser as the photo activator. The results of the treatment of 8 patients with EMPD were analyzed. Nearly $80 \%$ of those treated with PDT using porfimer sodium as PS showed complete response and were disease-free. In the case of ALA-PDT, $50 \%$ of lesions treated showed complete response and $38 \%$ were feverish from the disease after treatment (123). In 2011 Talreja et al. from the University of Virginia Health System, described their experience with the use of PDT for unresectable cholangiocarcinoma and the contribution of single-operator cholangioscopy (SOC) for targeted treatment. 45 patients were treated with PDT for cholangiocarcinoma during a five-year period. The analysis of the conducted studies showed that SOC allows for targeted therapy during PDT and can be successfully performed without adverse events while reducing radiation exposure (124). Rigual et al. in 2013 determined the safety of PDT with 2-(1-hexyloxyethyl)-2-devinyl pyropheophorbide-a (HPPH) in combination with surgery in patients with head and neck squamous cell carcinoma. 16 patients were injected intravenously with HPPH and then activated with $665 \mathrm{~nm}$ laser light in a surgical bed immediately after tumor resection. Disease sites included the larynx, mouth, skin, auditory canal and oropharynx. Research results have shown that HPPH-PDT can be used as a safe and effective method of treating head and neck cancers (125). Huggett et al. in 2014 they conducted PDT research using Verteporfin in locally advanced pancreatic cancer. 15 inoperable patients with locally advanced patients were treated with PDT. The study results showed that Verteporfin PDT-induced tumor necrosis in locally advanced pancreatic cancer is feasible and safe (126). Kanick et al. in 2015, they examined the feasibility of using protoporphyrin IX (PpIX) measurements in changes in actinic keratosis as a predictive biomarker of response to ALA-PpIX PDT. A non-invasive fiber-optic fluorescence spectroscopy system was used to measure PpIX concen- 
tration in patients undergoing standard-of-care ALA-PDT for AK. 70 patients took part in the study. Research results have shown that optical measurements of PpIX concentration obtained before light delivery can be used as an objective predictor of response to ALA-PpIX PDT (127). DeWitt et al. in 2019 they conducted research on PDT under the control of endoscopic ultrasound (EUS) in locally advanced pancreatic cancer (LAPC). 12 patients with previously untreated LAPC received intravenous porfimer sodium, followed by EUS-PDT after $48 \mathrm{~h}$. As a result of EUS-PDT, measurable imaged tumor necrosis registered, and the method itself proved to be safe for patients (128).

\section{PDD and PDT in Canada - clinical trials (Figure} 13)

Muller and Wilson in 1990 published the results of research on PDT of malignant brain tumors. The study involved 45 patients who were administered PS in the form of porphyrins around the day before PDT. Photoactivation of PS was induced with light at $630 \mathrm{~nm}$ wavelength introduced into the tumor cavity formed by tumor resection or tumor cyst drainage. The mortality rate of the surgery was $4 \%$, and 12 patients had a complete or nearly complete response to PDT. Research has shown that PDT of malignant brain tumors can be carried out at an acceptable risk. Positive results of PDT treatment were associated with adequate light delivery to the tumor (129). Kashtan et al. in 1991 they conducted a pilot study to determine the effica- cy of PDT in palliative advanced rectal cancer. Six patients with advanced rectal cancer were treated with PDT after Photofrin II photosensitization. In this study, a new intraluminal delivery system was incorporated. Five patients had clinical and radiological responses to treatment. Research has shown that PDT may become an alternative in the treatment of rectal cancer (130). In 1996, Muller and Wilson used PDT to treat patients with newly diagnosed malignant supratentorial gliomas. Intravenous porphyrin PS was administered $12-36 \mathrm{~h}$ prior to surgery and photo illumination. The test results did not show any undesirable effects due to the effects of PDT. The therapy used proved to be a safe method of treatment in newly diagnosed patients with supratentorial malignant gliomas (131). Scheider et al. in 1997 they used PDT for the treatment of tumor ingrowth in expandable esophageal stents. The study conducted in 4 patients with obstructive adenocarcinomas of the distal esophagus. The use of PDT alleviated swallowing disorders in all patients. The results showed that PDT accumulation for the treatment of tumor ingrowth is an effective and safe method (132). Yang et al. in 2003 they developed a multispectral fluorescence imaging system for intraoperative tumor identification. The system has been tested in pilot studies in patients with brain tumor resection, with or without intra-operative PhotofrinPDT. The designed imaging system has clearly shown red Photofrin fluorescence post radical resection in all PDT patients, with biopsy confirmation of residual tumor tissue in regions that were not seen as

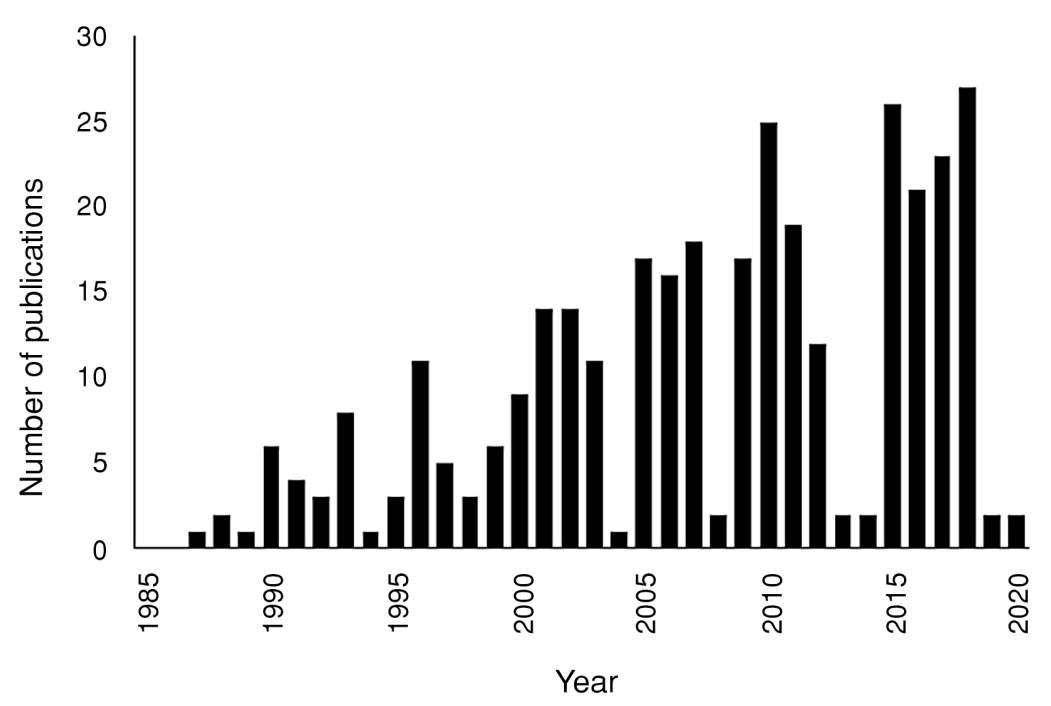

Figure 13. Number of scientific publications on research into photodynamic therapy in Canada (excluding review articles). The chart was based on searches in the PubMed database. 


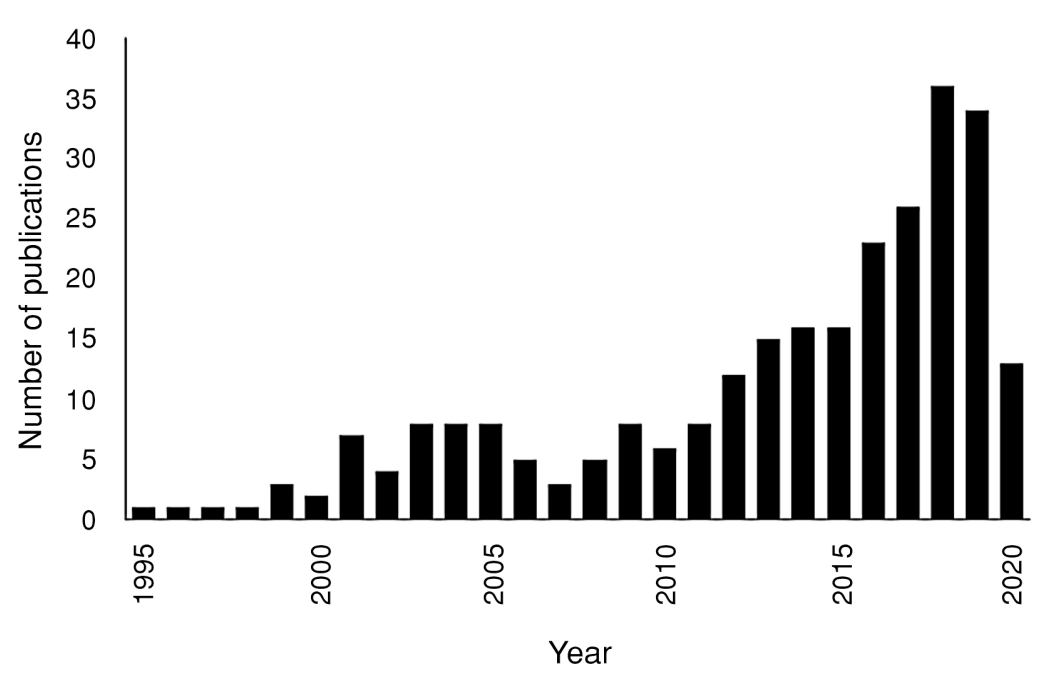

Figure 14. Number of scientific publications on research into photodynamic therapy in Russia (excluding review articles). The chart was based on searches in the PubMed database.

tumors under white light. The system proved effective in dosimetry and monitoring of PDT (133). Lui et al. in 2004 they examined the safety and efficacy of PDT with Verteporfin as PS in the treatment of multiple nonmelanoma skin cancers. The studies included 54 patients with 421 skin cancers without melanoma. Efficacy in fighting the tumor after PDT coverage was from $69 \%$ at $60 \mathrm{~J} / \mathrm{cm}^{2}$ to $93 \%$ at 180 $\mathrm{J} / \mathrm{cm}^{2}$. Research results have shown that even a single PDT cycle has therapeutic benefits in patients with multiple skin cancers without melanoma (134). Bissonnette et al. in 2010, they conducted a study on PDT with methylaminolevulinate (MAL) as PS, to assess the safety and efficacy of patients with facial acne. 44 patients were treated with PDT. The use of MAL-PDT allowed reducing the number of inflammatory lesions in patients with facial acne (135).

\section{PDD and PDT in Russia - clinical trials (Figure 14)}

Chissov et al. in 1994 they published a paper in which they described the results of research on PDT and fluorescence diagnostics of malignant tumors using Photogem. 60 patients with primary and metastatic malignant tumors of the breast, skin, respiratory and digestive organs, female reproductive organs, and urinary bladder participated in the study. A total of 48 patients underwent a single PDT session, and 11 had two PDT sessions. Patients received PS Photogem, which was developed in Russia. The exposure time was between 3 and 45 minutes. As a result of PDT, in $62 \%$ of cases, complete regression of the tumor was found, in $34 \%$ of cases partial regression was found, while in the remaining 4 cases no positive effects of therapy were found (136). A year later, Chissov et al. conducted research on fluorescent diagnostics of tumors using photosensitization to light. A spectroscopic fluorescence detection system was used to diagnose lung, larynx, skin, sting, and esophagus cancers. 22 patients took part in the study. The HpD (Photogem) types used in PS studies were characterized by selective retention in malignant tumors. The results of the research showed that the boundaries of the tumor before PDT treatment can be determined with the use of PS and fluorescence (137). In the years 1992 - 2006 at P.A. Hertsen Moscow Oncology Research Institute performed PDT therapy in 48 esophageal cancer patients, which was reported by Filonenko et al. in 2008. Russian PS (Photogem, Photosens, Radachlorin, Alasens) and endoscopic equipment were used for PDT. As a result of PDT, complete regression was observed in $77 \%$ of esophageal cancer changes, and partial regression in 23\% (138). Kochneva et al. in 2010 they conducted PDT clinical trials in patients with basal cell skin cancer. Radachlorin was used as PS as an intravenous infusion solution and as a topical gel. A 662 $\mathrm{nm}$ laser was used to activate PS. Studies have shown no side effects and good tolerance to PS by patients. Optimal results of treatment were obtained after $1.0-1.2 \mathrm{mg} / \mathrm{kg}$ PS and 4 irradiation sessions after 3 hours (139). In the years 2011-2013 PDT was performed in patients with precancer and cancer of penile, as reported by Filonenko et al. in 2015. PDT in 11 patients was performed using two meth- 
ods. In the first method, PS was applied topically, in the second, PS was administered intravenously. Alasen was used for topical application as PS, while Radachlor was used for intravenous injection. Nine patients achieved complete regression and 2 patients achieved partial regression due to PDT. In addition, the patients did not show any complications during or after treatment (140). In 2016, transurethral resection (TUR) combined with PDT with alasens for bladder cancer tests were performed. TUR and PDT were performed in 45 patients with a verified diagnosis of non-muscle-invasive bladder cancer. A single PDT session was conducted immediately after TUR. No complications were observed as a result of the therapy. In $78 \%$ of patients, no relapses were observed after therapy (141). Akopov et al. in 2017 they conducted a study in which fluorescence measurements of PS accumulation in the malignant tumor were performed and the rate of PS consumption during PDT was assessed. 45 patients with centrally located non-small cell lung cancer. Patients were divided into two groups, where in the first group a standard PDT procedure was used using $662 \mathrm{~nm}$ light, while in the second group PDT was performed under fluorescence control after irradiation of the area with violet light at $408 \mathrm{~nm}$. Studies have shown that $96 \%$ of patients showed intense fluorescence in the area of tracheal / bronchial tumor stenosis. The results showed that the use of fluorescence control allows for better optimization of the PDT procedure (142). Lapchenko et al. in 2018 performed research aimed at using PDT to increase the effectiveness of treatment of consequences of the gunshot wounds and mine-blast injuries inflicted on the face, head, and neck. PDT was carried out in 20 patients with gunshot wounds and face, head and neck injuries. The use of PDT allowed to prevent the development of serious complications, reduce the number of drug therapies, and significantly reduce the duration of treatment. Studies have shown the high effectiveness of the proposed approach (143). In 2019 at the Sechenov University Oncology Center in Moscow, PDT treatment was conducted in patients with nonresectable bile duct carcinoma complicated by obstructive jaundice. Intravascular diagnosis of malignant changes in the bile duct was performed using the endovideofluorescence module for minimally invasive surgery and endoscopy. The module used enabled tumor imaging and determination of high levels of photosensitizer accumulation in all 33 patients with bile duct cancer. The results of the study showed an extension of patients' lives. The use of fluorescence localization followed by PDT resulted in better results in the treatment of tumors (144).

\section{PDD and PDT in China - clinical trials (Figure 15)}

In 1990, Guo published the results of studies in which argon laser PDT was used in the treatment of 104 superficial bladder tumors in 40 patients. Optical fibers have been used to provide light to the bladder mucosa area. The study results showed that all patients achieved a complete response and only 7 patients recurred (145). Li et al. in 1990 they used PDT to treat malignant tumors. Studies carried out

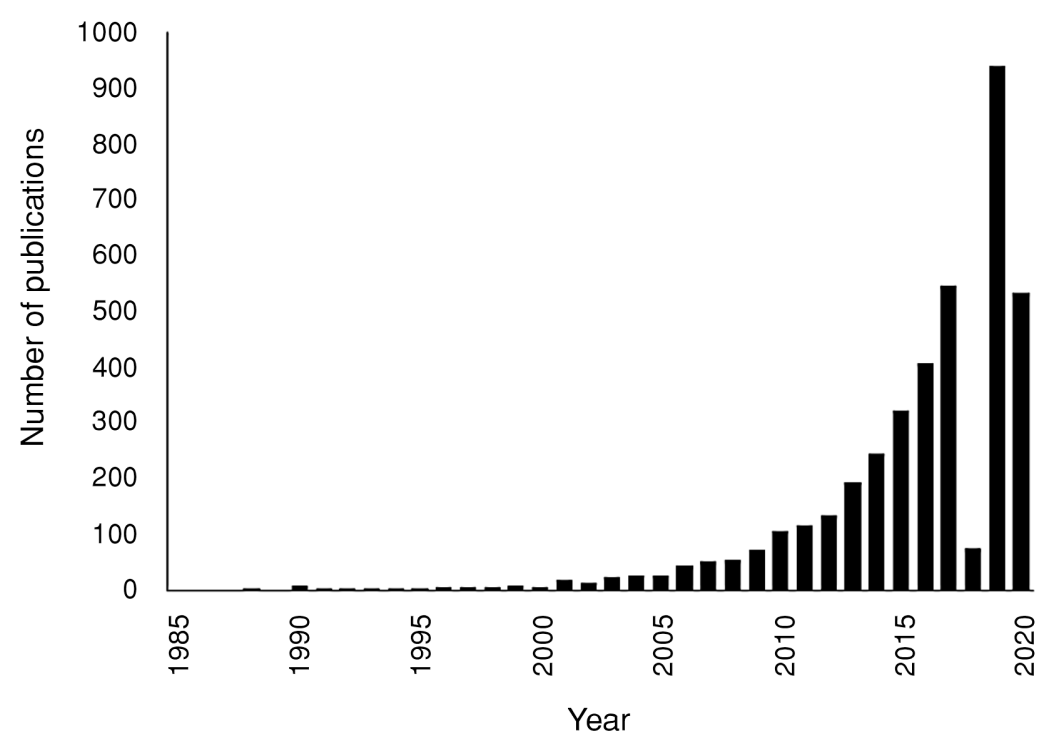

Figure 15. Number of scientific publications on research into photodynamic therapy in China (excluding review articles). The chart was based on searches in the PubMed database. 
in Beijing in 1982 - 1985 included patients with 540 cases of various cancers. The PS used in the therapy was an intravenously administered hematoporphyrin (HpD) derivative. As a result of PDT complete response was obtained in 227 cases, partial response was obtained in 114 cases, the mild response was obtained in 120 cases and 79 cases showed no response. In addition, the $\mathrm{HpD}$ fluorescence study performed for 409 cases of malignant neoplasms revealed changes in 344 cases (146). Jin et al. in 1991 they evaluated PDT in the treatment of advanced gastrointestinal cancer. In total, 142 patients with advanced gastrointestinal cancers were treated by PDT in 1982-1988. All patients 48-72 hours before PDT were given intravenous $\mathrm{HpD}$. The results of the study showed that a total of 100 patients had a response to PDT and the therapy was effective (147). In 1992, Jin et al. conducted a study combining PDT with chemotherapy to treat advanced cardiac cancers. In the years 1982 - 1990, a total of 144 patients were treated. Patients received intravenous $\mathrm{HpD}$ before PDT. The results showed that in patients treated with PDT in combination with chemotherapy, complete remission was achieved in nearly $20 \%$ of patients. Combining PDT with chemotherapy has been shown to be effective in the treatment of advanced cardiac cancers (148). Jin et al. in 1994 they performed PDT treatment in 207 patients with advanced upper gastrointestinal cancers. HpD was again used as PS. Response to PDT was seen in 146 patients, with complete response in 31 patients (149). Jiang et al. in 1998 they assessed the assessment of the curative effectiveness of PDT for port wine stain (PWS). 24 patients suffering from PWS participated in the study. The lesions were located on the face and neck. The PS in the form of $\mathrm{HpD}$ used in therapy showed high effectiveness in the treatment of PWS. The use of PDT resulted in lightened close to normal skin color without causing any scarring (150). Xu et al. in 2002, they published the results of a study on the effectiveness of PDT of skin cancers with partial differential alpha-aminolevulinic acid (ALA-PDT). 88 patients were treated for PDT, including 34 of basal cell carcinoma (BCC), 32 cases of squamous cell carcinoma (SCC). In BCC and SCC, a complete response was achieved in $100 \%$ of cases as a result of PDT treatment (151). Chan et al. in 2004 they conducted a study to determine the efficacy of PDT with verteporfin as a treatment for symptomatic polypoidal choroidal vasculopathy (PCV). Verteporfin was administered intravenously to 22 patients with 22 eyes presenting with serosanguinous maculopathy due to PCV. As a result of PDT, a stable or improved vision was achieved in 21 of the 22 eyes at the 1-year follow-up (152). In 2005, Chen et al. investigated the effect of PDT in combination with interstitial chemotherapy on gliomas. Only 2 out of 28 patients had a recurrence of glioma within 1 year after surgery. Studies have shown that PDT in combination with interstitial chemotherapy after microsurgery provides safe and effective treatment for glioma (153). Xiong and Zhang used PDT in 5 patients diagnosed as circumscribed choroidal hemangioma $(\mathrm{CCH})$. PDT has proved to be an effective method in the treatment of $\mathrm{CCH}$ serous retinal detachments resolved completely as a result of therapy (154). Liu et al. in 2009 they examined the efficacy and safety of PDT with topical 5-aminolaevulinic acid (ALA) for the treatment of cervical condylomata acuminate. 30 patients were included in the study. The applied therapy turned out to be a simple, effective, safe, well-tolerated, and low recurrence rate treatment for cervical condylomata acuminate (155). Lu et al. in 2012 they conducted studies in which 40 cases of perianal condyloma acuminata were treated with topical aminolevulinic acid PDT (ALA-PDT) combined with curettage. After 3 PDT sessions following surgical curettage, all 40 patients were cured and there was no recurrence at one month off treatment (156). Zhang et al. in 2013 they applied ALA-PDT treatment of nasal inverted papilloma. The applied therapy allowed to remove papilloma lesions and was well tolerated by patients (157). In 2014, Zhou et al. used PDT for the treatment of juvenile-onset laryngeal papillomatosis. PDT was performed during the first surgery, 20 days after, and 30 days after surgery. This was the world's first successful reported case of the use of PDT treatment for juvenile laryngeal papillomatosis (158). Fu et al. in 2016 examined the clinical effectiveness of ALA-PDT for cervical high-risk HPV (HR-HPV) infection. The treatment group 39 patients received three treatments of ALA-PDT at two-week intervals. Research results have shown that PDT is an effective, safe and well-tolerated treatment for cervical HR-HPV infection (159). Fan et al. in 2018 they conducted a study in which they used ALA-PDT for rosacea in Chinese patients. 20 patients with either erythematotelangiectatic or papulopustular type participated in the study. All patients showed gradual clinical improvement after therapy. ALA-PDT has proven to be an effective method in the treatment of rosacea. However, some patients have experienced short-term side effects, including erythema, swelling and discoloration (160). In 2019, Hu et al. conducted the treatment of condyloma acuminatum (CA) using the combina- 
tion of laser ablation and ALA-PDT. The study included 100 diagnosed CA cases. As a result of PDT, almost $94 \%$ of the total cure was achieved among the treated patients (161).

\section{PDD and PDT in Japan - clinical trials (Figure 16)}

Kato et al. in 1986 they performed PDT using $\mathrm{HpD}$ as PS to treat a patient with lung cancer. This was the first report showing that PDT could be effective in treating malignant lung lesions (162). Okunaka et al. in 1991 they published the results of studies on PDT in the treatment of patients with central lung cancer. A total of 145 patients were treated with PDT at Tokyo Medical College. Studies have shown that PDT was useful and improved prognosis in patients with many primary bronchial cancers (163). Research conducted by Furuse et al. confirmed the effectiveness of PDT in the early stages of lung cancer. As a result of PDT, 50 out of 59 treated patients showed complete response after therapy (164). In 1995, Uchibayashi et al. used PDT with $\mathrm{HpD}$ in 34 patients with refractory carcinoma in situ (CIS) of the bladder. As a result of HpD-PDT 25 of 34 patients had achieved a complete response. Research results have shown the high potential of this method in the treatment of bladder CSI (165). Mimura et al. in 1996 they conducted a clinical trial of PDT with Photofrin II and excimer dye laser for early gastric cancer. The effect of PDT was evaluated in 27 patients. During the studies, a slight mild skin reaction lasting up to several weeks was observed. No more side effects were recorded. Full responses were obtained in $88 \%$ of patients, and the total response rate was $100 \%$. PDT has proved to be an effective method in the treatment of early gastric cancer (166). In 2000, Itoh et al. conducted topical delta-aminolevulinic acid-based PDT (ALA-PDT) for Japanese actinic keratosis (AK). ALA-PDT was used in 9 patients with a total of 53 lesions. The rates of AK cure on the face, including neck and limbs, were $81.8 \%$ and $55.6 \%$, respectively (167). Itoh et al. in 2001 published the results of studies in which ALA-PDT was used to treat acne vulgaris. The therapy was used in 13 patients. PDT has been shown to be beneficial in the treatment of acne (168). Kato et al. in 2003 they conducted a clinical study of PDT Using mono-L-aspartyl Chlorin e6 (NPe6) and diode laser for early superficial squamous cell carcinoma of the lung. 40 patients with 45 lesions were eligible for safety evaluation, and 35 patients with 39 lesions were judged as eligible for efficacy evaluation of PDT treatment. The study showed excellent anti-cancer effects and safety in patients with early-stage lung cancer. The complete response was observed in nearly 85 percent of the changes (169). Yamaguchi et al. in 2005 used PDT to treat for cervical intraepithelial neoplasia (CIN). All patients received intravenous photofrin followed by PDT using a $630 \mathrm{~nm}$ wavelength laser. PDT proved to be an effective and minimally invasive CIN treatment. In addition, PDT has also been shown to eliminate HPV infection (170). Usudo et al. in 2010 used NPe6-PDT in 75 patients with centrally located

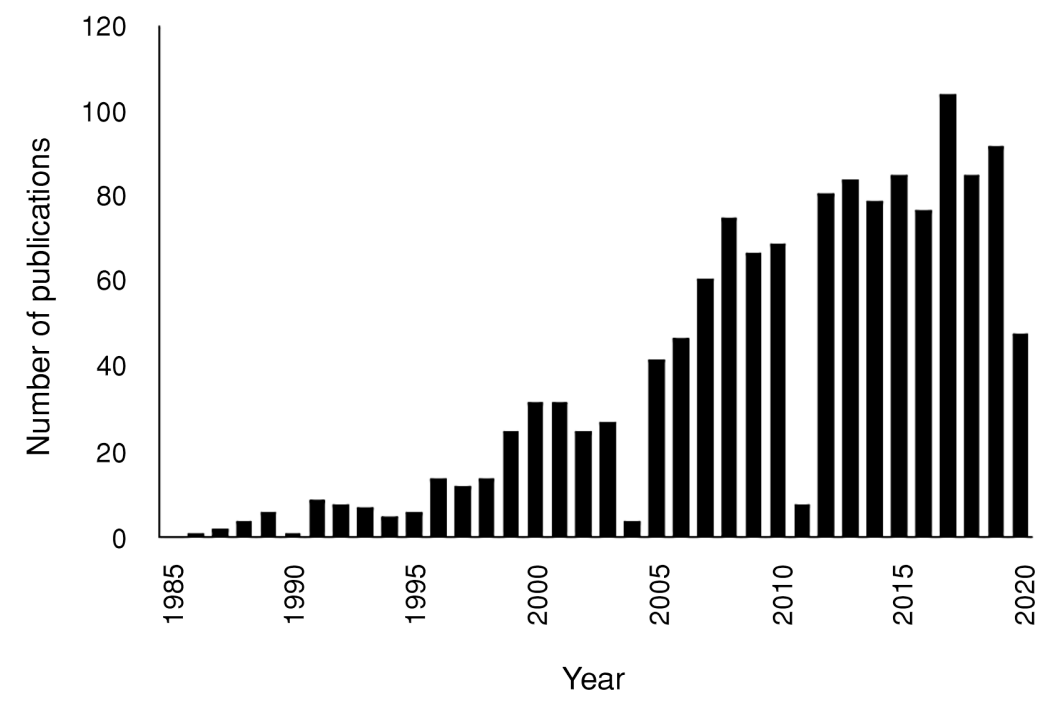

Figure 16. Number of scientific publications on research into photodynamic therapy in Japan (excluding review articles). The chart was based on searches in the PubMed database. 
early lung cancer less than $1 \mathrm{~cm}$ in diameter. PDT showed very high efficiency $(94 \%)$ in combating tumors with a diameter not exceeding $1 \mathrm{~cm}$ (171). Akimoto et al. in 2012 examined the safety and efficacy of PDT using talaporfin sodium in patients with surgically, completely unresectable malignant gliomas with invasion into the eloquent areas of the brain. PDT treatment was used as an additional treatment in 14 patients with malignant gliomas. The tumor resection site was irradiated with a 664 $\mathrm{nm}$ diode laser for 180 seconds. The results showed that PDT achieved a response rate of $80 \%$ in 6 patients with newly diagnosed malignant gliomas. In patients with recurrent tumors, the response to PDT was low and was $25 \%$ (172). Ikeda et al. in 2013 they presented the treatment outcome of photofrin-based PDT for T1 and T2 oral squamous cell carcinoma and dysplasia. A total of 30 regions in 25 patients were treated by PDT. A complete response was achieved in 24 of the 25 patients, with a partial response found in the remaining patient (173). Assessment of the usefulness of a novel highresolution magnifying video endoscope capable of PDD and PDT in experimental and clinical situations, conducted by Nakamura et al. in 2015. The fluorescences of three PSs (Photofrin, protoporphyrin IX and talaporfin sodium) were studied. After close endoscopic examinations, Photofrin were intravenously injected into the 5 patients for PDT, and 5-aminolevulinic acid (ALA) was orally taken for PDD. PDD was successfully performed in every patient. A complete response was obtained in $71.4 \%$ of tumors in five patients after PDT (174).

Current clinical and experimental PDT studies are represented in Figures 17 and 18.

\section{CONCLUSION}

Imaging techniques such as MRI and flow cytometry have become critical tools for guided PDT

\section{Clinical studies on PDT}
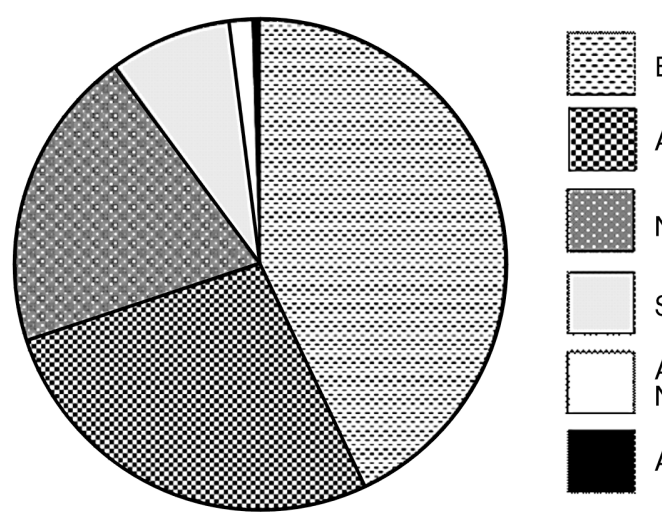

Europe $-43 \%$

Asia $-27 \%$

North America - $20 \%$

South America - $8 \%$

Australia and

New Zealand $-1.5 \%$

Africa $-0.5 \%$

Figure 17. The number of scientific publications based on the search for clinical photodynamic therapy in the PubMed database.

\section{Experimental studies on PDT}
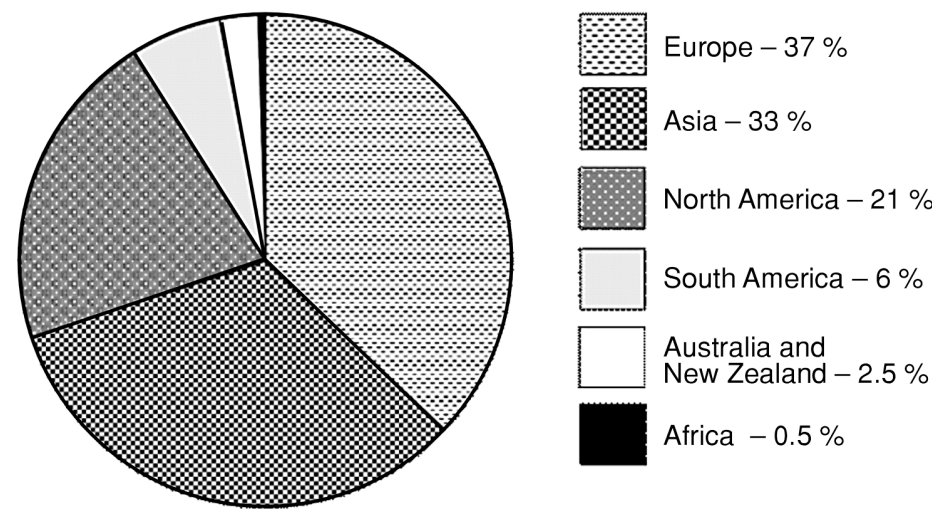

Figure 18. The number of scientific publications based on the search for experimental photodynamic therapy in the PubMed database. 
and visualization of cancer cell photosensitizer uptake. Recent advances in MRI detectable nanoparticle constructs, gadolinium-based photosensitizers, and europium singlet oxygen sensors can aid in the further development of deep tissue PDT. Applications of functional MRI using blood oxygen dependent levels (BOLD) can monitor PDT in deep tissue by detecting differences in oxygen concentration.

\section{Acknowledgments}

Dorota Bartusik-Aebisher received Grant New drug delivery systems-MRI study, Grant OPUS-13 issue 2017/25/B/ST4/02481.

\section{Conflict of interest}

The authors declare no conflict of interest.

\section{REFERENCES}

1. Hung J., Lam S., Leriche J.C.: Lasers Surg. Med. 11, 99 (1991).

2. Policard A.: C. R. Soc. Biol. 91, 1423 (1924).

3. Vahrmeijer A.L., Hutteman M., van der Vorst J.R., van de Velde C.J.H., Frangioni J.V.: Nat. Rev. Clin. Oncol. 10, 507 (2013).

4. D'Ippolito G., Torres L.R., Saito Filho C.F., Ferreira R.M.: Q. J. Nucl. Med. Mol. Imaging. 55, 603 (2011).

5. Alfano R.R.: Technol. Cancer Res. Treat. 10, 101 (2011).

6. Stringer M., Moghissi K.: Photodiagnosis Photodyn. Ther. 1, 9 (2004).

7. Allison R.R., Sibata C.H.: Photodiagnosis Photodyn.Ther. 5, 247 (2008).

8. Borisova E., Vladimirov B., Ivanova R., Avramov L.: New Techniques in Gastrointestinal Endoscopy. Shanghai: inTech-Rijeka. pp. 231-252 (2011).

9. Pinthus J.H., Bogaards A., Weersink R., Wilson B.C., Trachtenberg J.: J. Urol. 175, 1201 (2006).

10. Alimova A., Katz A., Siddique M., Minko G., Savage HE., et al.: IEEE Sens. J. 5, 704 (2005).

11. Deyl Z., Praus R., Šulcová H., Goldman JN.: FEBS Lett. 5, 187 (1969).

12. Richards-Kortum R.: Annu. Rev. Phys. Chem. 47, 555 (1996).

13. Lakowicz J.R., Szmacinski H., Nowaczyk K., Johnson M.L.: Proc. Natl. Acad. Sci. 89, 1271 (1992).

14. van den Berg P.A., van Hoek A., Walentas C.D., Perham R.N., Visser A.J.: Biophys. J. 74, 2046 (1998).
15. Polo C.F., Frisardi A.L., Resnik E.R., Schoua A.E., Batlle A.M.: Clin. Chem. 34, 757 (1988).

16. Pinthus J.H., Bogaards A., Weersink R., Wilson B.C., Trachtenberg J.: J. Urol. 175: 1201 (2006).

17. Whitmore W.F., Jr. Bush I.M., Esquivel E.: Cancer 17, 1528 (1964).

18. Frimberger D., Zaak D., Stepp H., Knüchel R., Baumgartner R., et al.: Urology 58, 372 (2001).

19. Saarnak A.E., Rodriguez T., Schwartz J., Moore A.L., Moore T.A., et al.: Lasers Med. Sci. 13, 22 (1998).

20. Jocham D., Stepp H., Waidelich R.: Eur. Urol. 53, 1138 (2008).

21. Schomacker K.T., Frisoli J.K., Compton C.C., Flotte T.J., Richter J.M., et al.: Lasers Surg. Med. 12, 63 (1992).

22. Zalesska-Kręcicka M., Kręcicki T., Frączek M., Bereś-Pawlik E., Zatoński T.: Otolaryngol. Pol. 59, 195 (2005) (in Polish).

23. Osada T., Arakawa A., Sakamoto N., Ueyama H., Shibuya T., et al.: World J. Gastroenterol. 17, 5110 (2011).

24. Sieroń-Stołny K., Kwiatek S., Latos W., Kawczyk-Krupka A., Cieślar G., et al.: Photodiagnosis Photodyn. Ther. 9, 5 (2012).

25. Frimberger D., Schneede P., Hungerhuber E., Sroka R., Zaak D., et al.: Urol. Res. 30, 295 (2002).

26. Herth F.J., Ernst A., Becker H.D.: Respiration. 70, 395 (2003).

27. Hewett J., Nadeau V., Ferguson V., Moseley H., Ibbotson S., et al.: Photochem. Photobiol. 73, 278 (2001).

28. Zargi M., Fajdiga I., Smid I.: Eur. Arch. Otorhinolaryngol. 257, 17 (2000).

29. Richards-Kortum R., Sevick-Muraca E.: Annu. Rev. Phys. Chem. 47, 555 (1996).

30. Andersson-Engels S., Klinteberg C., Svanberg K., Svanberg S.: Phys. Med. Biol. 42, 815 (1997).

31. Lam S., Kennedy T., Unger M., Miller Y.E., Gelmont D., et al.: Chest 113, 696 (1998).

32. Chen W., Gao X., Tian Q., Chen L.: Lung Cancer 73, 183 (2011).

33. Wang Y., Wang Q., Feng J., Wu Q.: Patient Prefer. Adherence 7, 621 (2013).

34. Iftikhar I.H., Musani A.I.: Ther. Adv. Respir. Dis. 9, 207 (2015).

35. Zaric B., Perin B., Stojsic V., Carapic V., Eri Z., et al.: Med. Oncol. 30, 374 (2013).

36. Li M., Izumo T., Zhang G., Peng A., Wang C.: Zhonghua Yi. Xue. Za. Zhi. 94, 3497 (2014). 
37. Shibuya K., Nakajima T., Fujiwara T., Chiyo M., Hoshino H., et al.: Lung Cancer 69, 194 (2010).

38. Ohtani K., Lee A.M., Lam S.: Respirology 17, 261 (2012).

39. Wellikoff A.S., Holladay R.C., Downie G.H., Chaudoir C.S., Brandi L., Turbat-Herrera E.A.: Respirology 20, 967 (2015).

40. Sorokina A., Danilevskaya O., Averyanov A., Zabozlaev F., Sazonov D., et al.: Respirology. 19, 907 (2014).

41. Thiberville L., Salaün M., Lachkar S., Dominique S., Moreno-Swirc S., et al.: Eur. Respir. J. 33, 974 (2009).

42. Fuchs F.S., Zirlik S., Hildner K., Schubert J., Vieth M., Neurath M.F.: Eur. Respir. J. 41, 1401 (2013).

43. Fuchs F.S., Zirlik S., Hildner K., Frieser M., Ganslmayer M.: Respiration 81, 32 (2011).

44. Gillenwater A., Jacob R., Ganeshappa R., Kemp B., El-Naggar A.K., et al.: Arch. Otolaryngol. Head. Neck. Surg. 123, 1251 (1998).

45. De Veld D.C., Witjes M.J., Sterenborg H.J., Roodenburg J.L.: Oral. Oncol. 41, 117 (2005).

46. de Paula D'Almeida C., Campos C., Nogueira M.S., Pratavieira S., Kurachi C.: Biophotonics South Am. 9531, 953146 (2015).

47. Farwell D.G., Meier J.D., Park J., Sun Y., Coffman H., et al.: Arch. Otolaryngol. Head. Neck. Surg. 136, 126 (2010).

48. Gratton E., Breusegem S., Sutin J.D.B., Ruan Q., Barry N.P.: J. Biomed. Opt. 8, 381 (2003).

49. Gallety N.P., McGinty J., Dunsby C., Teixeira F., Requejo-Isidor J., et al.: Br. J. Dermatol. 159, 152 (2008).

50. Patalay R., Talbot C., Munro I., Breunig H.G., König K., et al.: SPIE. BiOS. 7883, 78830A (2011).

51. Lotan Y.: Urol. Oncol. 33, 261 (2015).

52. Kutwin P., Konecki T., Cichocki M., Falkowski P., Jabłonowski Z.: Photomed. Laser. Surg. 35, 459 (2017).

53. Zaak D., Frimberger D., Stepp H., Wagner S., Baumgartner R., et al.: J. Urol. 166, 1665 (2001).

54. Ziolkowski P., Osiecka B.J., Siewinski M., Bronowicz A., Ziolkowska J., GerberLeszczyszyn H.: J. Environ. Pathol. Toxicol. Oncol. 25, 403 (2006).

55. Olejek A., Kozak-Darmas I., Kellas-Sleczka S., Steplewska K., Biniszkiewicz T., et al.: Neuro. Endocrinol. Lett. 30, 547 (2009).

56. Osiecka B., Jurczyszyn K., Ziółkowski P.: Med. Sci. Monit. 18, 5 (2012).
57. Kawczyk-Krupka A., Waśkowska J., Raczkowska-Siostrzonek A., Kościarz-Grzesiok A., Kwiatek S., et al.: Photodiagnosis Photodyn. Ther. 9, 148 (2012).

58. Maździarz A., Zielińska A., Alkhalayla H., Spiewankiewicz B.: Photodiagnosis Photodyn. Ther. 10, 422 (2013).

59. Pietruska M., Sobaniec S., Bernaczyk P., Cholewa M., Pietruski J.K., et al.: Photodiagnosis Photodyn. Ther. 11, 34 (2014).

60. Osiecka B.J., Jurczyszyn K., Nockowski P., Murawski M., Ziółkowski P.: Photodiagnosis Photodyn. Ther. 2017, 185 (2017).

61. Osiecka B.J., Nockowski P., Szepietowski J.C.: Acta Derm. Venereol. 98, 689 (2018).

62. Jocham D., Beer M., Baumgartner R., Staehler G., Unsöld E.: Ciba Found. Symp. 146, 198 (1989).

63. Kriegmair M., Waidelich R., Lumper W., Ehsan A., Baumgartner R., Hofstetter A.: J. Urol. 154, 1339 (1995).

64. Szeimies R.M., Karrer S., Sauerwald A., Landthaler M.: Dermatology 192, 246 (1996).

65. Feyh J.: J. Photochem. Photobiol. B. 36, 175 (1996)

66. Messmann H., Szeimies R.M., Bäumler W., Knüchel R., Zirngibl H., et al.: Endoscopy 29, 275 (1997)

67. Waidelich R., Hofstetter A., Stepp H., Baumgartner R., Weninger E., Kriegmair M.: J. Urol. 159, 401 (1998).

68. Schmidt-Erfurth U., Miller J., Sickenberg M., Bunse A., Laqua H., et al.: Graefes Arch. Clin. Exp. Ophthalmol. 236, 365 (1998).

69. Hillemanns P., Korell M., Schmitt-Sody M., Baumgartner R., Beyer W., et al.: Int. J. Cancer 81, 34 (1999).

70. Berr F., Wiedmann M., Tannapfel A., Halm U., Kohlhaw K.R., et al.: Hepatology 31, 291 (2000).

71. Löning M., Diddens H., Küpker W., Diedrich K., Hüttmann G.: Cancer 100, 1650 (2004).

72. Stepp H., Beck T., Pongratz T., Meinel T., Kreth F.W.: J. Environ. Pathol. Toxicol. Oncol. 26, 157 (2007).

73. Berking C., Herzinger T., Flaig M.J., Brenner M., Borelli C., Degitz K.: Dermatol. Surg. 33, 825 (2007).

74. Soergel P., Wang X., Stepp H., Hertel H., Hillemanns P.: Lasers Surg. Med. 40, 611 (2008).

75. Adam C., Salomon G., Walther S., Zaak D., Khoder W., et al.: Eur. Urol. 55, 1281 (2009).

76. Johansson A., Faber F., Kniebühler G., Stepp H., Sroka R., et al.: Lasers Surg. Med. 45, 225 (2013). 
77. Hillemanns P., Wimberger P., Reif J., Stepp H., Klapdor R.: Lasers Surg. Med. 49, 169 (2017).

78. von Dobbeler C., Schmitz L., Dicke K., Szeimies R.M., Dirschka T.: Photodiagnosis Photodyn. Ther. 27, 198 (2019).

79. Hugh-Jones P., Gardner W.N.: Q. J. Med. 64, 565 (1987).

80. Stender I.M., Wulf H.C.: Br. J. Dermatol. 135, 454 (1996).

81. Stender I.M., Lock-Andersen J., Wulf H.C.: Clin. Exp. Dermatol. 24, 154 (1999).

82. Nybaek H., Jemec G.B.: Dermatology 211,135 (2005).

83. Wiegell S.R., Wulf H.C.: J. Am. Acad. Dermatol. 54, 647 (2006).

84. Christiansen K., Bjerring P., Troilius A.: Lasers Surg. Med. 39, 302 (2007).

85. Wiegell S.R., Haedersdal M., Eriksen P., Wulf H.C.: Br. J. Dermatol. 160, 1308 (2009).

86. Hermann G.G., Mogensen K., Carlsson S., Marcussen N., Duun S.: B.J.U. Int. 108, 297 (2011).

87. Haak C.S., Togsverd-Bo K., Thaysen-Petersen D., Wulf H.C., Paasch U., et al.: Br. J. Dermatol. 172, 215 (2015).

88. Perria C.: J. Neurosurg. Sci. 32, 99 (1988).

89. Corti L., Mazzarotto R., Belfontali S., De Luca C., Baiocchi C., et al.: J. Photochem. Photobiol. B 36, 193 (1996).

90. Patelli M., Lazzari Agli L., Poletti V., Falcone F.: Monaldi Arch. Chest Dis. 54, 315 (1999).

91. Corti L., Skarlatos J., Boso C., Cardin F., Kosma L., et al.: Int. J. Radiat. Oncol. Biol. Phys. 47, 419 (2000).

92. Porrini G., Giovannini A., Amato G., Ioni A., Pantanetti M.: Ophthalmology 110, 674 (2003).

93. Fossarello M., Peiretti E., Zucca I., Serra A.: Cornea 22, 485 (2003).

94. Rossi R., Puccioni M., Mavilia L., Campolmi P., Mori M., et al.: J. Chemother. 16, 306 (2004).

95. Surrenti T., De Angelis L., Di Cesare A., Fargnoli M.C., Peris K.: Eur. J. Dermatol. 17, 412 (2007).

96. Bombeccari G.P., Guzzi G., Gualini F., Gualini S., Santoro F., Spadari F.: Implant Dent. 22, 631 (2013).

97. Serini S.M., Cannizzaro M.V., Dattola A., Garofalo V., Del Duca E., et al.: J. Cosmet. Dermatol. 18, 156 (2019).

98. Freche C., De Corbiere S.: J. Photochem. Photobiol. B. 6, 291 (1990).

99. Foultier M.T., Vonarx-Coinsman V., de Brito L.X., Morlet L., Robillard N., Patrice T.: Cancer 73, 1595 (1994).
100. Quaranta M., Mauget-Fa`sse M., Coscas G.: Am. J. Ophthalmol. 134, 277 (2002).

101. Etienne J., Dorme N., Bourg-Heckly G., Raimbert P., Fléjou J.F.: Gastrointest. Endosc. 59, 880 (2004).

102. Maunoury V., Mordon S., Bulois P., Mirabel X., Hecquet B., Mariette C.: Dig. Liver. Dis. 37, 491 (2005).

103. Trachtenberg J., Weersink R.A., Davidson S.R., Haider M.A., Bogaards A., et al.: BJU Int. 102, 556 (2008).

104. Basset-Seguin N., Ibbotson S.H., Emtestam L., Tarstedt M., Morton C., et al.: Eur. J. Dermatol. 18, 547 (2008).

105. Azzouzi A.R., Barret E., Moore C.M., Villers A., Allen C., et al.: BJU Int. 112, 766 (2013).

106. Lebdai S., Bigot P., Leroux P.A., Berthelot L.P., Maulaz P., Azzouzi A.R.: J. Urol. 198, 335 (2017).

107. McCaughan Jr J.S.: Cancer Invest. 8, 407 (1990).

108. Harlow S.P., Rodriguez-Bigas M., Mang T., Petrelli N.J.: Ann. Surg. Oncol. 2, 228 (1995).

109. Takita H., Dougherty T.J.: Semin. Surg. Oncol. 11, 368 (1995).

110. McCaughan J.S. Jr., Ellison E.C., Guy J.T., Hicks W.J., Jones J.J., et al.: Ann. Thorac. Surg. 62, 1005 (1996).

111. Nseyo U.O.: J. Clin. Laser Med. Surg. 14, 271 (1996).

112. Webber J., Kessel D., Fromm D.: J. Photochem. Photobiol. B 38, 209 (1997).

113. Taber S.W., Fingar V.H., Wieman T.J.: J. Surg. Oncol. 68, 209 (1998).

114. Overholt B.F., Panjehpour M., Haydek J.M.: Gastrointest. Endosc. 49, 1 (1999).

115. Krishnamurthy S., Powers S.K., Witmer P., Brown T.: Lasers Surg. Med. 27, 224 (2000).

116. Madreperla S.A.: Arch. Ophthalmol. 119, 1606 (2001).

117. Spaide R.F., Donsoff I., Lam D.L., Yannuzzi L.A., Jampol L.M., et al.: Retina 22, 529 (2002).

118. Barbazetto I.A., Lee T.C., Rollins I.S., Chang S., Abramson D.H.: Am. J. Ophthalmol. 135, 898 (2003).

119. Friedberg J.S., Mick R., Stevenson J.P., Zhu T., Busch T.M., et al.: J. Clin. Oncol. 22, 2192 (2004).

120. Bakri S.J., Beer P.M.: Eye (Lond). 19, 795 (2005).

121. Richey D.F., Hopson B.: J. Drugs. Dermatol. 5, 12 (2006).

122. Tierney E.P., Eide M.J., Jacobsen G., Ozog D.: J. Cosmet. Laser. Ther. 10, 81 (2008). 
123. Housel J.P., Izikson L., Zeitouni N.C.: Dermatol. Surg. 36, 1718 (2010).

124. Talreja J.P., DeGaetani M., Sauer B.G., Kahaleh M.: Photochem. Photobiol. Sci. 10, 1233 (2011).

125. Rigual N.R., Shafirstein G., Frustino J., Seshadri M., Cooper M., et al.: JAMA Otolaryngol. Head Neck Surg. 139, 706 (2013).

126. Huggett M.T., Jermyn M., Gillams A., Illing R., Mosse S., et al.: Br. J. Cancer 110, 1698 (2014).

127. Kanick S.C., Davis S.C., Zhao Y., Sheehan K.L., Hasan T., et al.: Photodiagnosis Photodyn. Ther. 12, 561 (2015).

128. DeWitt J.M., Sandrasegaran K., O’Neil B., House M.G., Zyromski N.J., et al.: Gastrointest. Endosc. 89, 390 (2019).

129. Muller P.J., Wilson B.C.: Can. J. Neurol. Sci. 17, 193 (1990).

130. Kashtan H., Papa M.Z., Wilson B.C., Deutch A.A., Stern H.S.: Dis. Colon. Rectum. 34, 600 (1991).

131. Muller P.J., Wilson B.C.: J. Clin. Laser. Med. Surg. 14, 263 (1996).

132. Scheider D.M., Siemens M., Cirocco M., Haber G.B., Kandel G., et al.: Endoscopy 29, 271 (1997).

133. Yang V.X.D., Muller P.J., Herman P., Wilson B.C.: Lasers Surg. Med. 32, 224 (2003).

134. Lui H., Hobbs L., Tope W.D.T., Lee P.K., Elmets C., et al.: Arch. Dermatol. 140, 26 (2004).

135. Bissonnette R., Maari C., Nigen S., Provost N., Bolduc C.: J. Drugs Dermatol. 9, 1347 (2010).

136. Chissov V.I., Skobelkin O.K., Mironov A.F., Smirnov V.V., Sokolov V.V., et al.: Khirurgiia (Mosk) 12, 3 (1994).

137. Chissov V.I., Sokolov V.V., Filonenko E.V., Menenkov V.D., Zharkova N.N., et al.: Khirurgiia (Mosk) 5, 37 (1995).

138. Filonenko E.V., Sokolov V.V., Chissov V.I., Lukyanets E.A., Vorozhtsov G.N.: Photodiagnosis Photodyn. Ther. 5, 187 (2008).

139. Kochneva E.V., Filonenko E.V., Vakulovskaya E.G., Scherbakova E.G., Seliverstov O.V., et al.: Photodiagnosis Photodyn. Ther. 7, 258 (2010).

140. Filonenko E., Kaprin A., Alekseev B., Urlova A.: Biomed. Res. Int. 2015, 245080 (2015).

141. Filonenko E.V., Kaprin A.D., Alekseev B.Y., Apolikhin O.I., Slovokhodov E.K., et al.: Photodiagnosis Photodyn. Ther. 16, 106 (2016).
142. Akopov A.L., Rusanov A.A., Papayan G.V., Kazakov N.V., Gerasin A.V., et al.: Photodiagnosis Photodyn. Ther. 19, 73 (2017).

143. Lapchenko A.S., Kucherov A.G., Order R.Y., Lapchenko A.A.: Vestn. Otorinolaringol. 83, 62 (2018).

144. Shiryaev A.A., Musaev G.K., Levkin V.V., Reshetov I.V., Loshchenov M.V., et al.: Photodiagnosis Photodyn. Ther. 26, 218 (2019).

145. Guo Y.C.: Zhonghua Zhong Liu Za Zhi. 12, 75 (1990).

146. Li J.H., Guo Z.H., Jin M.L., Zhao F.Y., Cai W.M., et al.: J. Photochem. Photobiol. B 6, 149 (1990).

147. Lin M.L., Yang B.Q., Zhang W., Ren P.: J. Clin. Laser Med. Surg. 9, 45 (1991).

148. Jin M.L., Yang B.Q., Zhang W., Ren P.: J. Photochem. Photobiol. B 12, 101 (1992).

149. Jin M., Yang B., Zhang W., Wang Y.: Semin. Surg. Oncol. 10, 111 (1994).

150. Jiang L., Gu Y., Li X., Zhao X., Li J., et al.: Chin. Med. J. (Engl) 111, 136 (1998).

151. Xu S., Wang X., Xu W., Xia Y., Zhang C.: Chin. Med. J. (Engl) 115, 1141 (2002).

152. Chan W.M., Lam D.S., Lai T.Y., Liu D.T., Li K.K., et al.: Ophthalmology 111, 1576 (2004).

153. Chen L.F., Ke Y.Q., Yang Z.L., Wang S.Q., Xu R.X.: Di. Yi. Jun. Yi. Da. Xue. Xue. Bao. 25, 116 (2005).

154. Xiong Y., Zhang F.: Zhonghua. Yan. Ke. Za. Zhi. 43, 1085 (2007).

155. Liu Y.X., Zheng H.Y., Liu X.R.: Chin. Med. Sci. J. 24, 151 (2009).

156. Lu Y.G., Yang Y.D., Wu J.J., Lei X., Cheng Q.H., et al.: Photomed. Laser Surg. 30, 186 (2012).

157. Zhang Y., Yang Y., Zou X.: Photodiagnosis Photodyn. Ther. 10, 549 (2013).

158. Zhou C., Sun B., Wang F., Dai Z., Han Z., et al.: World J. Surg. Oncol. 12, 275 (2014).

159. Fu Y., Bao Y., Hui Y., Gao X., Yang M., et al.: Photodiagnosis Photodyn. Ther. 13, 29 (2016).

160. Fan L., Yin R., Lan T., Hamblin M.R.: Photodiagnosis Photodyn. Ther. 24, 82 (2018).

161. Wang H., Li W., Zhang D., Li W., Wang Z.: Aust. Dent. J. 64, 256 (2019).

162. Kato H., Konaka C., Kawate N., Shinohara H., Kinoshita K., et al.: Chest 90, 768 (1986).

163. Okunaka T., Kato H., Konaka C., Kawate N., Bonaminio A., et al.: Cancer 68, 253 (1991).

164. Furuse K., Fukuoka M., Kato H., Horai T., Kubota K., et al.: J. Clin. Oncol. 11, 1852 (1993).

165. Uchibayashi T., Koshida K., Kunimi K., Hisazumi H.: Br. J. Cancer 71, 625 (1995). 
166. Mimura S., Ito Y., Nagayo T., Ichii M., Kato H., et al.: Lasers Surg. Med. 19, 168 (1996).

167. Itoh Y., Ninomiya Y., Henta T., Tajima S., Ishibashi A.: J. Dermatol. 27, 513 (2000).

168. Itoh Y., Ninomiya Y., Tajima S., Ishibashi A.: Br. J. Dermatol. 144, 575 (2001).

169. Kato H., Furukawa K., Sato M., Okunaka T., Kusunoki Y., et al.: Lung Cancer 42, 103 (2003).

170. Yamaguchi S., Tsuda H., Takemori M., Nakata S., Nishimura S., et al.: Oncology 69, 110 (2005).

() 2020 by Polish Pharmaceutical Society. This is an access article under the CC BY NC license

\footnotetext{
(http://creativecommons.org/licenses/by-nc/4.0/).
}

171. Usuda J., Ichinose S., Ishizumi T., Kayashi K., Ohtani K., et al.: Clin. Cancer Res. 16, 2198 (2010).

172. Akimoto J., Haraoka J., Aizawa K.: Photodiagnosis Photodyn. Ther. 9, 91 (2012).

173. Ikeda H., Tobita T., Ohba S., Uehara M., Asahina I.: Photodiagnosis Photodyn. Ther. 10, 229 (2013).

174. Nakamura T., Oinuma T., Yamagishi H., Masuyama H., Terano A.: Photodiagnosis Photodyn. Ther. 12, 115 (2015). 